\title{
Drug Addiction, Dysregulation of Reward, and Allostasis
}

\author{
George F. Koob, Ph.D., and Michel Le Moal, M.D., Ph.D.
}

This paper reviews recent developments in the neurocircuitry and neurobiology of addiction from a perspective of allostasis. A model is proposed for brain changes that occur during the development of addiction that explain the persistent vulnerability to relapse long after drug-taking has ceased. Addiction is presented as a cycle of spiralling dysregulation of brain reward systems that progressively increases, resulting in the compulsive use and loss of control over drug-taking. The development of addiction recruits different sources of reinforcement, different neuroadaptive mechanisms, and different neurochemical changes to dysregulate the brain reward system. Counteradaptive processes such as opponent-process that are part of normal homeostatic limitation of reward function fail to return within the normal homeostatic range and are hypothesized to form an allostatic state. Allostasis from the addiction perspective is defined as the process of maintaining apparent reward function stability by changes in brain reward mechanisms. The allostatic state represents a chronic deviation of reward set point and is fueled not only by dysregulation of reward circuits per se, but also by the activation of brain and hormonal stress responses. The manifestation of this allostatic state as compulsive drugtaking and loss of control over drug-taking is hypothesized to be expressed through activation of brain circuits involved in compulsive behavior such as the cortico-striatal-thalamic loop. The view that addiction is the pathology that results from an allostatic mechanism using the circuits established for natural rewards provides a realistic approach to identifying the neurobiological factors that produce vulnerability to addiction and relapse.

[Neuropsychopharmacology 24:97-129, 2001] (C) 2000 American College of Neuropsychopharmacology. Published by Elsevier Science Inc.
KEY WORDS: Allostasis; Drug addiction; Reward dysregulation

\section{BACKGROUND}

Drug addiction is a chronically relapsing disorder that is defined by two major characteristics: a compulsion to take the drug with a narrowing of the behavioral reper-

From the Department of Neuropharmacology, The Scripps Research Institute, La Jolla, CA, USA (GFK); and Psychobiologie des Comportements Adaptatifs, INSERM, Unite 259, Universite de Bordeaux II, Bordeaux, France (MLM).

Address correspondence to: George F. Koob, Ph.D., Department of Neuropharmacology, CVN-7, The Scripps Research Institute, 10550 North Torrey Pines Road, La Jolla, CA 92037.

Received 5 July 2000; revised 18 August 2000; accepted 25 August 2000 toire toward excessive drug intake, and a loss of control in limiting intake (American Psychiatric Association 1994; World Health Organization 1992). An important challenge for neurobiological research is to understand the neuroadaptive differences between controlled drug use and loss of control, and by extension, the molecular, cellular and system processes that lead to addiction (Koob and Le Moal 1997).

Animal models are critical for understanding the neuropharmacological mechanisms involved in the development of addiction. While there are no complete animal models of addiction, animal models do exist for many elements of the syndrome. These elements can be derived from symptoms or diagnostic criteria for addiction or conceptual frameworks such as different sources of reinforcement (American Psychiatric Association 1994; World Health Organization 1992). Linking neu- 
ropharmacological events to animal models can occur at multiple levels of analysis - molecular, cellular and system - and it will only be the integration of these changes across dimensions of analysis that will allow a full understanding of the neurobiology of drug addiction.

Advances in neuroscience research are rapidly unraveling the complexity of processes underlying addiction in general and of drug abuse in particular. Assuming that the reductionist approach is useful in bringing about precise knowledge concerning biologic aspects of addiction, new conceptual frameworks will be required to understand what has been labeled as "the quintessential biobehavioral disorder" (Leshner 1999), a disorder deeply imbedded with psychosocial vulnerability as well as genetic vulnerability (Koob and Le Moal 1997). Such an integrated pathogenic view of addiction has profound implications for the treatment of drug abuse, and the best therapeutic approaches include social, behavioral and biological aspects, in combination with pharmacotherapies (Baxter et al. 1992, 1996; McLellan et al. 1993; O'Brien 1997; Project MATCH Research Group 1997; Schwartz 1999).

Drugs of abuse act at local cellular-membrane sites, within neurochemical systems that are part of a reward system neurocircuitry. These systems include the dopamine and opioid peptide networks which have many different projection sites. The midbrain dopamine systems have critical roles not only in the reward and motor systems but also in higher-order functions, including cognition and memory (Grant et al. 1996). Opioid peptides have been implicated in pain and emotional processing throughout the neuraxis.

The mechanisms and processes leading from an initial cellular action of drugs of abuse to an action within reward circuits and beyond require a psychobiological integration that parallels the processes leading from use, to misuse, to abuse and dependence and vulnerability to relapse. Addicted patients are gripped by unusual emotional states, they compulsively have urges to abuse and they are remarkably unencumbered by the memory of negative consequences of drug-taking (Childress et al. 1999). These clinical states are hypothesized to be mirrored by a "brain signature" (Nestler and Aghajanian 1997), and modern imaging technologies help to see how such complex constructs, as compulsion to use drugs or compulsion to engage in repetitive dysfunctional behaviors, are implemented into brain networks including large and complex circuitries of the brain reward and emotional systems (Childress et al. 1999; Volkow et al. 1999). Other areas of psychobiological integration include the translation of animal research advances in the neurobiology of addiction to useful clinical studies and the development of conceptual frameworks that integrate both domains. The present review will examine the neurobiological mechanisms of addiction with a focus on dysregulation of the brain reward system and allostasis
(Koob and Le Moal 1997). Emphasis will be placed on integrating across the different levels of analysis in an attempt to identify what is known and what remains to be elucidated.

\section{ADDICTION CYCLE}

Drug addiction is not a static phenomenon, and as with other biobehavioral dysregulation, such as compulsive gambling and binge eating, there are different components that constitute a cycle or circle of ever-growing pathology (Baumeister et al. 1994). Derived from social psychology and conceptualized as sources of self-regulation failures, the addiction cycle has been described as having three components: preoccupation-anticipation, binge-intoxication, and withdrawal-negative affect (Koob and Le Moal 1997). Spiralling distress describes how, in some cases, the first self-regulation failure can lead to emotional distress, which sets up a cycle of repeated failures to self-regulate, and where each violation brings additional negative affect (Baumeister et al. 1994). Spiralling distress also has been described as the progressive dysregulation of the brain reward system within the context of repeated addiction cycles (Figure 1). Psychiatric and experimental psychological constructs address the same addiction cycle, and animal models have been established and validated for different symptoms or constructs associated with elements of the addiction cycle, addiction criteria, and sources of reinforcement associated with addiction (American Psychiatric Association 1994; Koob 1995; Koob et al. 1998a; Markou et al. 1993).

Superimposed on the addiction cycle are multiple sources of reinforcement that can contribute to compulsive use of drugs of abuse during the course of drug addiction. Positive reinforcement occurs when presentation of the drug increases the probability of a response to obtain the drug again. The positive reinforcing effects of drugs when described in the context of reward often are equated with the pleasurable effects of drugs in the absence of a deficit state. Negative reinforcement, in contrast, occurs with alleviation of an existing aversive state or alleviation of a drug-generated aversive state (e.g., withdrawal) (Wikler 1973). Secondary positive reinforcing effects can be obtained through conditioned positive reinforcement (e.g., pairing of previously neutral stimuli with acute positive reinforcing effects of drugs). Secondary negative reinforcing effects can be obtained through removal of the conditioned negative reinforcing effects of conditioned abstinence. Positive reinforcement as a construct is associated largely with the binge intoxication stage outlined in Figure 1, and the construct of negative reinforcement is associated largely with the negative affect/withdrawal stage. Conditioned positive reinforcement and condi- 


\section{Criteria for Substance Dependence (DSM-IV)}

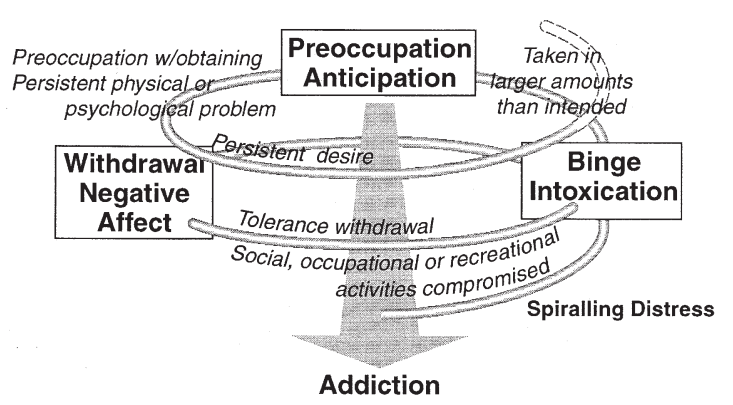

Figure 1. Diagram describing the spiralling distress/addiction cycle from a psychiatric perspective with the different criteria for substance dependence from the Diagnostic and Statistical Manual of Mental Disorders, 4th edition, incorporated at different stages. There are three major components of the addiction cycle: preoccupation-anticipation, binge-intoxication, and withdrawal-negative affect. From an experimental psychology perspective, different sources of reinforcement correspond to different components of the addiction cycle with the binge-intoxication component largely associated with positive reinforcement and the withdrawal-negative affect component largely associated with negative reinforcement. Conditioned positive and conditioned negative reinforcement would be hypothetically associated with the preoccupationanticipation component. The theoretical constructs of psychomotor sensitization and counteradaptation also vary with the stage of the cycle, with psychomotor sensitization probably having a greater role in the preoccupation-anticipation stage and counteradaptation having a greater role in the withdrawal-negative affect component (Koob and Le Moal 1997). Similarly, the hypothetical role of different neurochemical/ endocrine systems in the addiction cycle would fall into different components. The binge-intoxication component is reflected by activation of dopaminergic and opioid peptide systems, and the withdrawal-negative affect component is dominated by decreases in dopamine and opioid peptide function and increases in brain stress systems such as CRF. Note that the addiction cycle is conceptualized as a spiral that increases in amplitude with repeated experience, ultimately resulting in the pathological state known as addiction. (Taken with permission from Koob and Le Moal 1997.)

tioned negative reinforcement can be conceptualized to contribute to the preoccupation/anticipation stage.

The neurobiological bases for the acute positive reinforcing effects of drugs of abuse, the negative reinforcing effects imparted by the dependent state, and the conditioned reinforcing effects associated with protracted abstinence (defined as a state of residual reward dysregulation after acute withdrawal) and relapse have provided significant insight into the building blocks of addiction (Koob et al. 1993). However, linking the animal models to the different components of the criteria used to diagnose substance dependence in humans requires a conceptual framework that will have heuristic value for explaining compulsive use and loss of control that are not inherent components of any one source of reinforcement. A transition occurs between limited access, controlled drug use (e.g., social drinking), and the loss of control and compulsive use of alcohol that constitutes alcoholism and to date few conceptual frameworks have bridged that gap. The hypothesis under exploration here is that drug addiction not only involves changes in the neural substrates of positive reinforcement but that other neuroadaptive systems are recruited, notably in the domains of reward and stress to produce changes in motivational systems. Such changes are hypothesized to contribute to an allostatic state that renders the organism vulnerable to the spiralling distress and pathology of addiction (see below).

\section{STRESS}

Stress has been defined historically as responses to demands (usually noxious) upon the body (Selye 1936), or in a definition more focused on the central nervous system, as alterations in psychological homeostatic processes (Burchfield 1979). A state of stress is associated with various external and internal challenges to the body and brain, usually termed stressors, and the construct of stress may represent the extreme pathological continuum of overactivation of the normal activational (arousal) or emotional systems of the body (Hennessy and Levine 1979). Such arousal-activational mechanisms trigger biological and behavioral strategies of coping and control that mobilize many organismic and central nervous system mechanisms, whose failure leads to illness (McEwen 1998a; Schulkin et al. 1994; Sterling and Eyer 1981). The state of stress is reflected biologically by various physiological changes that include an activation of the pituitary-adrenal axis and release of glucocorticoids into the bloodstream (Stanford and Salmon 1993), activation of the sympathetic nervous system, and activation of brain emotional systems.

Pituitary-adrenal axis activation is triggered by the release of adrenocorticotropic hormone (ACTH) from the pituitary. ACTH release is in turn controlled by the liberation of hypothalamic corticotropin-releasing factor (CRF) into the pituitary portal system of the median eminence. Extrahypothalamic CRF systems are involved in the adaptive autonomic nervous system, and behavioral changes are another major component of the response to bodily demands or challenges to homeostasis (Koob et al. 1993). Evidence demonstrating a neurotropic role for CRF in the central nervous system outside the pituitary-adrenal axis suggests a parallel means for mediating autonomic and behavioral responses to stressors and a contribution to the behavioral state of stress in addition to the classic activation of adrenal steroids (Figures 2A, and 2B; for a more integrated review, see below and Figure 3 ). 


\section{A \\ Hypothalamic-Pituitary-Adrenal Brain Stress System}

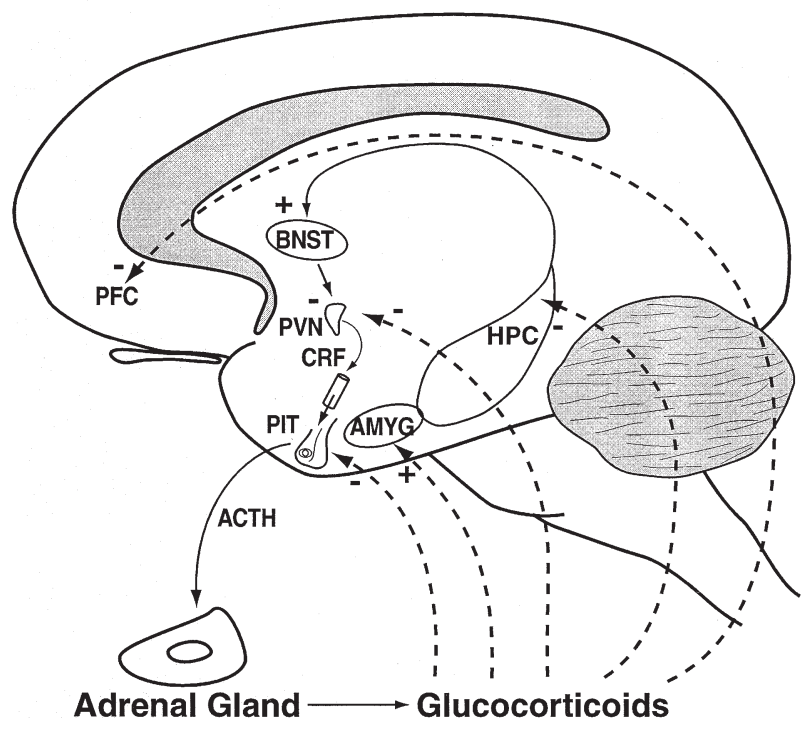

B

\section{Extra Hypothalamic CRF Brain Stress System}

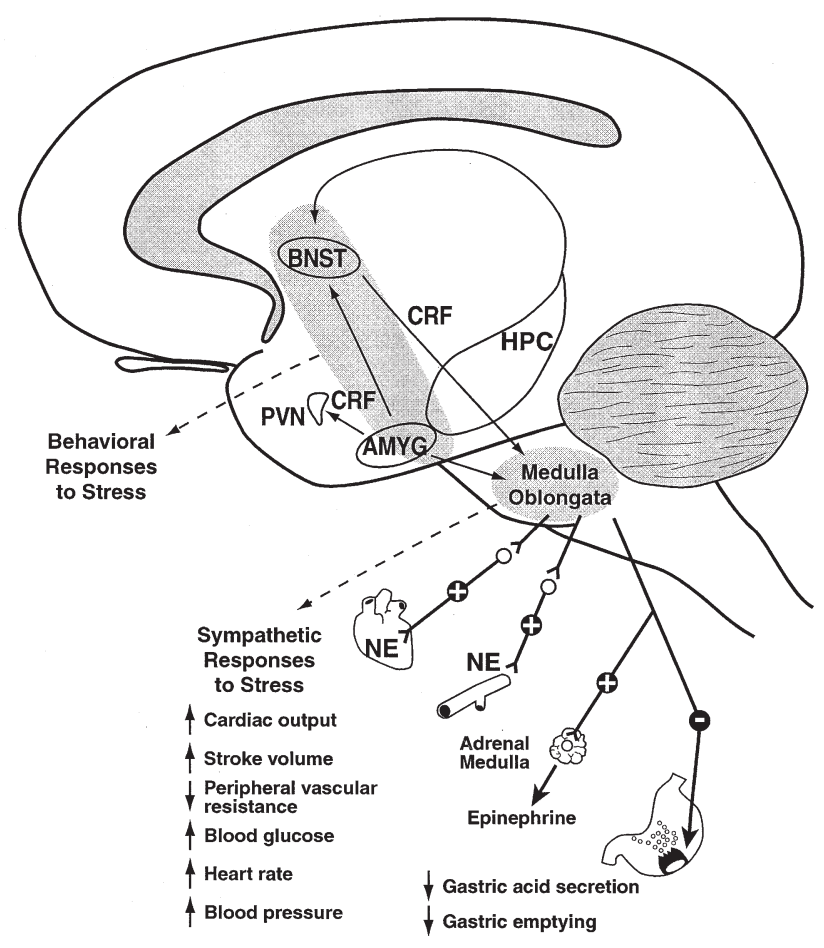

Figure 2. Diagrams illustrating the central role of corticotropin-releasing factor in the (A) hypothalamic-pituitary-adrenal stress axis, and (B) the brain stress systems. The functional interactions between glucocorticoids, CRF and stress represent an exquisitely balanced stress system. (A) Hypothalamic-pituitary-adrenal stress system. Stressful stimuli increase CRF which in turn stimulates ACTH release from the pituitary which results in enhanced release of glucocorticoids from the adrenal gland. High levels of glucocorticoids, through negative feedback, decrease CRF synthesis at the level of the PVN but activate CRF activity at the level of the central nucleus of the amygdala. (B) Extrahypothalamic CRF stress system. Stressful stimuli also activate CRF systems in the basal forebrain, notably the bed nucleus of the stria terminalis and the central nucleus of the amygdala to help mediate behavioral responses to stressors and to mediate sympathetic activation associated with stressors. Glucocorticoids, instead of exerting a feedback suppression of CRF synthesis in the central nucleus of the amygdala, actually increase synthesis of CRF providing a means for extending the contribution of the brain stress systems to allostasis (see text). ACTH, adrenocorticotropic hormone; AMYG, amygdala; BNST, bed nucleus of the stria terminalis; $\mathrm{CRF}$, corticotropin-releasing factor; HPC, hippocampus; NE, norepinephrine; PIT, pituitary gland; PFC, prefrontal cortex; PVN, paraventricular nucleus. 


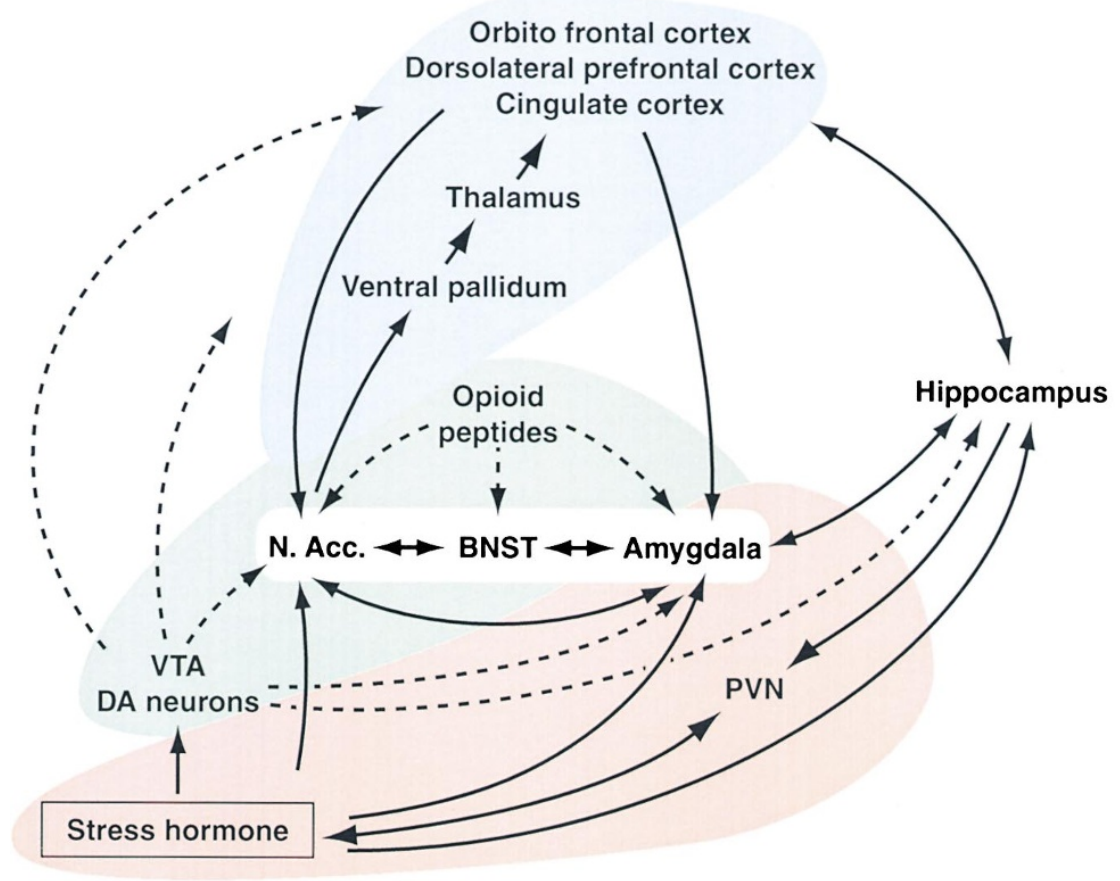

Figure 3. Circuit diagram illustrating the hypothesized extended amygdala reward system as a focal point for allostasis in addiction and the interaction of two major brain circuits that help perpetuate the allostatic states in the brain reward system. Elements of the nucleus accumbens, bed nucleus of the stria terminalis and central nucleus of the amygdala have cytoarchitectual, circuit and functional similarities that have been hypothesized to form a key component of what has been conceptualized as a brain reward circuit. Critical, but not exclusive, modulatory neurochemical components of the brain reward circuit include the mesolimbic dopamine system and opioid peptides. Fueling dysregulation within the brain reward circuit are the HPA stress axis and brain stress systems, and expressing and perpetuating the dysregulation of reward in the form of compulsive behavior is the cortico-thalamic-striatal loop circuit (Swerdlow and Koob 1987). BNST, bed nucleus of the stria terminalis; DA, dopamine; N. Acc., nucleus accumbens; PVN, paraventricular nucleus; VTA, ventral tegmental area.

As noticed since the beginning of the stress concept (Selye 1976), as the process goes along (as coping, adjustment and successful adaptations fail), more and more neuroendocrine and neurobiological systems are recruited. The hormones that are beneficial when contained within the homeostatic range are a source of pathophysiological cascades when they remain persistently elevated due to a breakdown of negative feedback or a failure of feedback regulation of CRF and ACTH secretion. Ultimately, various peripheral and central pathological effects are hypothesized to ensue, such as an imbalance in noradrenergic systems which may enhance anxiety (Chrousos and Gold 1992), neural atrophy in the hippocampal CA3 region with cognitive consequences, and various endocrine and systemic disorders (e.g., elevated insulin, increased blood pressure, and so on) (for review see McEwen 1995).

\section{ALLOSTASIS}

Homeostasis, in principle, corresponds to the mechanisms that maintain stability within the physiological systems and hold all the parameters of the organisms internal milieu within limits that allow an organism to survive (Bernard 1865; Cannon and Rosenblueth 1933; Sterling and Eyer 1988). It implied originally that i) deviations from normal set points are automatically corrected by local negative feedbacks, and ii) bodily organs are considered as functioning autonomously. Subsequently, homeostasis has been described as a self-regulating process for maintaining body parameters around a set point critical for survival (McEwen 2000). This includes multi-system coordination of the organism's response to an acute challenge, including the brain, pituitary, autonomic system, and skeleto-motor systems. However, while some of the parameters of the internal milieu are held constant (like body temperature), other parameters like stress hormones are varied within a wide range in an attempt to maintain homeostasis.

In contrast, the principle of allostasis proposes maintenance of stability outside of the normal homeostatic range, where an organism must vary all the parameters of its physiological systems to match them appropriately to chronic demands (e.g., reset the system parameters at a new set point) (Sterling and Eyer 1988). Allostasis refers to the integrative adaptive processes maintaining stability through change, a stability that is 
not within the normal homeostatic range. It implies that many, if not all, physiological functions are mobilized or suppressed, as reflected in a cascade of brain-organism interactions overriding local regulation. By controlling all the mechanisms simultaneously, the brain can enforce its command and introduce experience, memories, anticipation and re-evaluation of needs in anticipation of physiological requirements.

The allostatic model, because it involves the whole brain and body instead of simply local feedbacks, is far more complex than homeostasis. All parameters of a given domain (e.g., blood pressure, or in the central nervous system reward function) are controlled by numerous mutually interacting signals. When demands become chronic, the brain-body system tonically adapts at essentially all levels of organization implying widespread changes in set points, and entry into a relaxed condition may create an unpleasant state of withdrawal from one's physiological regulation. Such changes in hormones, opioids, transmitters, and so on, provide a physiological basis for the individual to continue to seek a condition of high demand (Sterling and Eyer 1988), and a stabilized new level of activity far from homeostatic equilibrium. However, when chronic arousal, repeated stress and negative affective states impose prolonged regulations far from normality, there is no margin left for responding to additional challenges, no opportunity for relaxation, and no capacity for more responsiveness. This stabilized new level of activity far from homeostatic equilibrium forms an allostatic state. An allostatic state can be defined as a state of chronic deviation of the regulatory systems from their normal state of operation with establishment of a new set point.

This chronic stress and chronic arousal has been hypothesized to lead to breakdown, damaging consequences, and illness (Sterling and Eyer 1981). Allostatic load as defined by McEwen and Stellar (1993) refers to the cost or the price the body may have to pay for being forced to adapt to an adverse or deleterious psychological or physical situation, and it represents the presence of too much demand on the operation of the regulatory systems - mainly the primary mediators of the physiological response - or their failure to relax when the demand is over. Different types of allostatic load have been considered that may explain different types or gradients of morbidity (McEwen 1998a). Whatever the modality, the process is translated into a different structural-functional state (i.e., a vulnerable phenotype).

Thus, a simple definition of allostasis is a process of maintaining stability, or "apparent stability," through change but at a price (Sterling and Eyer 1988). With continuing demand, the flexibility to maintain stability through allostatic maladaptations decreases, leading to breakdown and illness. Here, drug addiction is hypothesized to involve a change in drug reward set point and reflects an allostatic, rather than a homeostatic, adapta- tion (i.e., outside the normal set point). Thus, in the addiction domain to be elucidated here, the stability to be maintained is stability in reward function and the change is the mobilization of multiple neurotransmitter and hormonal systems needed to maintain normal reward function. Reward neurotransmitters such as dopamine and opioid peptides are hypothesized to have a limited capacity to maintain reward function within homeostatic range.

The acute effects of initial drug intake and consequent glucocorticoid activation can extend this capacity but also can trigger the beginnings of counteradaptive mechanisms such as neuroadaptation within the dopamine and opioid peptide systems (presynaptic to postsynaptic to transduction mechanisms), and the recruitment of opposing systems such as activation of brain stress systems such as corticotropin-releasing factor and norepinephrine. Opponent-process counteradaptation is defined here as the opposing of the initial hedonic effects of a drug or stimulus by a slowly developing counteracting process that becomes larger over time and masks the initial hedonic effects of the drug or stimulus (Solomon and Corbit 1974). These counteradaptive mechanisms are hypothesized to form the driving force of a reward system allostatic state (increase in reward set point; see below). Carrying such a state of allostasis would be hypothesized to reflect both genetic and environmental factors that, when combined, render the individual vulnerable to entry into any one of a number of components of the addiction cycle. Thus, multiple brain and hormonal mechanisms can combine to produce the allostatic state that underlies the severe pathology of the "addicted" state.

Drawing from recent conceptualizations about allostasis, anxiety and negative affective states do not have a simple set point that is maintained and regulated (Schulkin et al. 1998). Chronic elevation of stress axis reactivity and central CRF, its gene expression in the amygdala, and loss of gene inhibition in the paraventricular nucleus by glucocorticoids beyond homeostatic regulation, may represent a condition of allostasis within the brain/hormonal stress system. Similar stress-like conditions also are found in drug dependence, withdrawal and craving for psychoactive agents where both CRF expression and cortisol levels are increased and may contribute to the allostatic state hypothesized to drive drug addiction. Such a chronic stress-like contribution to allostasis can extend also to other systems in the form of pathology to compromise sleep, feeding, immune function, and so on. Thus, for the purposes of this review, the following definitions apply: allostasis, the process of achieving stability through change (Sterling and Eyer 1981); allostatic state, a state of chronic deviation of the regulatory system from its normal (homeostatic) operating level; allostatic load, the cost to the brain and body of the deviation, ac- 
cumulating over time, and reflecting in many cases pathological states and accumulation of damage (McEwen and Stellar 1993).

\section{NEUROBIOLOGICAL MECHANISMS FOR THE POSITIVE REINFORCING EFFECTS OF DRUGS}

To understand how the brain reward systems are changed with the development of addiction, one must understand the neurobiological bases for drug reward, and there have been major advances in this domain of research. One of the principle focuses of research on the neurobiology of the positive reinforcing effects of drugs of abuse has been the origins and terminal areas of the mesocorticolimbic dopamine system, and there is now compelling evidence for the importance of this system in drug reward (Le Moal and Simon 1991). The major components of this drug reward circuit are the ventral tegmental area (the site of dopaminergic cell bodies), the basal forebrain (the nucleus accumbens, olfactory tubercle, amygdala, and frontal and limbic cortices), the dopaminergic connection between the ventral tegmental area and the basal forebrain, and opioid peptide neurons within these circuits. Other components are the many neural inputs and outputs that interact with the ventral tegmental area and the basal forebrain utilizing GABA, glutamate, and serotonin as neurotransmitters (Koob 1992).

The dopamine projections that modulate forebrain and cortical regions enable in normal conditions the integration of the functioning of these areas, some of these coordinated in parallel modular organizations (Le Moal 1995). At the core of these interrelations and imbalances (Figure 3), two related sets of structures are considered: the mesolimbic-accumbens-amygdaloid complex, with an emphasis on the extended amygdala and accumbens shell (Alheid and Heimer 1988; Heimer et al. 1991; Koob 1999b), and the cortico-frontal-cingulate complex related to a striatal-pallidal-thalamic circuitry (Figure 3). Dopamine projections to the first set of structures are functionally involved in the acute reinforcing effects of psychostimulants, and neurochemical changes associated with the motivational aspects of drug withdrawal may involve neuroadaptations within the extended amygdala (Koob 1999b; Di Chiara 1999).

Drug-seeking behavior under the control of reinforcing processes that result from conditioned or secondorder schedules of reinforcement may depend ultimately on this extended amygdala circuit and involve basolateral cortical projections to the core of the nucleus accumbens which is anatomically more related to striatal-pallidal circuitry (Everitt et al. 1999). Note that the central nucleus of the amygdala is connected with hypothalamic and brain-stem regions included in autonomic and consummatory responses, while the cortico- striatal-thalamic circuitry is comprised of regions implicated in motor learning, reinforcer evaluation (nucleus accumbens) or stimulus-reward associations (Jentsch and Taylor 1999). The cortico-striatal-thalamic circuitry is related more to cognitive functioning, to active inhibitory central mechanisms, drive and compulsive repetitive behaviors. Activation of these regions as visualized by imaging techniques in drug abuse during intense craving (Volkow and Fowler 2000) is the same as those visualized in obsessive-compulsive disorder (Baxter et al. 1992, 1996; Graybiel et al. 1994; Modell et al. 1989; Schwartz 1997).

Compulsive disorders and anxiety may in some cases point to a similar phenotype but via different origins. In anxiety associated with drug dependence, anticipatory angst and negative affect may trigger compulsive searching for the drug but the sequence might be different in other pathological conditions, such as obsessive compulsive behavior. Important points to consider are that these two structural-functional sets are connected and second that they are both modulated by dopamine (Le Moal 1995). Moreover, it is well documented that mesocortical dopamine and mesolimbic dopamine neurons have different physiological regulation, dopamine utilization in the nucleus accumbens being under the control of a cortical-accumbens excitatory pathway (for review see Le Moal and Simon 1991). Specific drugs may enter into this neurocircuitry at different points and via different molecular/cellular mechanisms (Table 1).

\section{Psychomotor Stimulants}

Psychomotor stimulants of high abuse potential interact initially to block monoamine transporter proteins which are located on monoaminergic nerve terminals. Cocaine inhibits all three monoamine transporters dopamine, serotonin, and norepinephrine - thereby,

Table 1. Neurobiological Substrates for the Acute Reinforcing Effects of Drugs of Abuse

\begin{tabular}{lll}
\hline Drug of Abuse & Neurotransmitter & \multicolumn{1}{c}{ Sites } \\
\hline $\begin{array}{c}\text { Cocaine and } \\
\text { amphetamines }\end{array}$ & $\begin{array}{l}\text { Dopamine } \\
\text { Serotonin }\end{array}$ & $\begin{array}{l}\text { Nucleus accumbens } \\
\text { Amygdala }\end{array}$ \\
Opiates & $\begin{array}{l}\text { Dopamine } \\
\text { Opioid peptides }\end{array}$ & $\begin{array}{l}\text { Ventral tegmental area } \\
\text { Nucleus accumbens }\end{array}$ \\
Nicotine & Dopamine & Ventral tegmental area \\
& Opioid peptides & Nucleus accumbens \\
& Amygdala \\
THC & Dopamine & Ventral tegmental area \\
Alcohol & Opioid peptides & \\
& Dopamine & Ventral tegmental area \\
& Opioid peptides & Nucleus accumbens \\
& Serotonin & Amygdala \\
& GABA & \\
\hline
\end{tabular}


potentiating monoaminergic transmission. Amphetamine and its derivatives also potentiate monoaminergic transmission by blocking reuptake and also by increasing monoamine release. Amphetamine itself is transported into monoaminergic nerve terminals by all three transporters, where it produces a reverse transport of the monoamine into the synaptic cleft via the monoamine transporters (Rudnick and Clark 1993).

The dopamine system appears to be the critical substrate for both the psychomotor stimulant effects of amphetamine and cocaine and their reinforcing actions since in studies of intravenous self-administration and studies of conditioned place preference dopamine receptor antagonists, when injected systemically, reliably decrease the reinforcing effects of cocaine and amphetamine self-administration in rats and block conditioned place preferences for these drugs (Beninger and Hahn 1983; Beninger and Herz 1986; Ettenberg et al. 1982; Morency and Beninger 1986; Phillips and Fibiger 1987; Yokel and Wise 1975). All three dopamine receptor subtypes have been implicated in the reinforcing actions of cocaine as measured by intravenous self-administration including the D1 (Koob et al. 1987), D2 (Bergman et al. 1990; Woolverton and Virus 1989), and D3 receptors (Caine and Koob 1993). Dopamine D1 and D2 antagonists also block the place conditioning produced by amphetamine (Beninger et al. 1989; Leone and Di Chiara 1987). The specific anatomical site for the rewarding action of cocaine and amphetamine appears to be the mesocorticolimbic dopamine system since dopamine lesions and microinjection of dopamine antagonists into the terminal regions of the mesocorticolimbic, but not nigrostriatal, dopamine system block cocaine and amphetamine reinforcement (Maldonado et al. 1993; Roberts et al. 1977, 1980).

\section{Opiates}

The acute reinforcing properties of opiates in nondependent animals are blocked by systemic and central administration of competitive opiate antagonists (Ettenberg et al. 1982; Goldberg et al. 1971; Koob et al. 1984; Vaccarino et al. 1985; Weeks and Collins 1976). Pharmacological studies have shown that the mu opioid receptor subtype appears to be particularly important for the reinforcing actions of heroin and morphine (Negus et al. 1993), and knockout mice without the mu receptor fail to show morphine-induced analgesia or morphineinduced conditioned place preference (Matthes et al. 1996). The sites of action for opioid antagonists to block the reinforcing effects of opiates appears to be associated with the same neural circuitry associated with psychomotor stimulant reward (Table 1). Much data suggest that neural elements in the region of the ventral tegmental area and the nucleus accumbens are responsible for the reinforcing properties of opiates and that there are both dopamine-dependent and dopamineindependent mechanisms of opiate action (Pettit et al. 1984; Shippenberg et al. 1992; Spyraki et al. 1983; Stinus et al. 1989).

\section{Alcohol and Sedative Hypnotics}

Alcohol and other sedative-hypnotics, such as barbiturates and benzodiazepines, all produce a characteristic euphoria, disinhibition, anxiety reduction, sedation, and hypnosis. There is much evidence implicating dopamine in the reinforcing actions of low, nondependence-inducing doses of alcohol. Dopamine receptor antagonists have been shown to reduce lever-pressing for alcohol in nondeprived rats (Pfeffer and Samson 1988), and extracellular dopamine levels also have been shown to increase in nondependent rats orally selfadministering low doses of alcohol (Weiss et al. 1992a). However, virtually complete 6-hydroxydopamine denervation of the nucleus accumbens failed to alter voluntary responding for alcohol (Rassnick et al. 1993c) suggesting that dopamine-independent, neurochemical systems likely contribute critically to the mediation of alcohol's reinforcing actions.

The sedative and anti-punishment (anxiolytic) effects of sedative-hypnotics are associated with facilitation of the $\mathrm{GABA}_{\mathrm{A}}$ receptor and/or inhibition of the NMDA glutamate receptor (Hoffman et al. 1989; Lovinger et al. 1989; Richards et al. 1991). GABAergic antagonists also reverse many of the behavioral effects of alcohol that are associated with intoxication (Frye and Breese 1982; Liljequist and Engel 1982). The partial inverse benzodiazepine agonist RO 15-4513, which has been shown to reverse some of the behavioral effects of alcohol (Suzdak et al. 1986), produces a dose-dependent reduction of oral alcohol (10\%) self-administration in rats (June et al. 1992; Rassnick et al. 1993a; Samson et al. 1987).

With central microinjection studies, potent GABA antagonists microinjected into the brain produced their most effective blockade when microinjected into the central nucleus of the amygdala (Hyytia and Koob 1995). Alcohol also appears to interact with specific serotonergic receptor systems, notably serotonin-1A, serotonin-2 and serotonin-3 (Eckardt et al. 1998; Roberts et al. 1998). Opioid receptor antagonists also decrease alcohol self-administration, and as a result alcohol long has been hypothesized to activate opioid peptide systems. Mice bearing knockout of the mu opioid receptor do not drink alcohol (Roberts et al. 2000b). The brain sites for such interactions are likely to be in the ventral tegmental area and basal forebrain (Gatto et al. 1994; Heyser et al. 1999). Thus, multiple neurotransmitters combine to contribute to the reward profile of alcohol (Engel et al. 1992). 


\section{Nicotine}

Nicotine is a direct agonist at nicotinic acetylcholine receptors which are widely distributed throughout the brain. The nicotinic receptors mainly implicated in the reinforcing actions of nicotine again are localized to the brain mesocorticolimbic dopamine system (Corrigall et al. 1992, 1994; Malin et al. 1993; Pontieri et al. 1996). However, peptide antagonists can interact with the nicotine withdrawal syndrome in rats (Malin et al. 1993, 1994; Watkins et al. 2000). Thus, nicotine may alter function in both the mesocorticolimbic dopamine system and opioid peptide systems in the same neural circuitry associated with other drugs of abuse (Corrigall et al. 1992).

\section{Tetrahydrocannabinol}

The major psychoactive ingredient in marijuana, tetrahydrocannabinol (THC), is a drug of abuse and dependence (Anthony et al. 1994). A major initial site of THC binding is the cannabinoid-1 receptor which is widely distributed throughout the brain, but it is particularly concentrated in the extrapyramidal motor system of the rat (Herkenham et al. 1990). Evidence for acute reinforcing effects of THC comes from studies of brain stimulation reward, place preference and intravenous self-administration. Reward thresholds are decreased by THC administration in rats upon acute administration (Gardner et al. 1988; Lepore et al. 1996), and THC also produces a place preference (Lepore et al. 1995). THC increases dopamine in the shell of the nucleus accumbens similar to that observed with other major drugs of abuse (Tanda et al. 1997). In addition, a recent study in mice has shown intravenous selfadministration of a synthetic THC analog (Fratta et al. 1997), and intravenous self-administration of THC in monkeys (Tanda et al. 2000). One substrate hypothesized for the acute reinforcing effects of THC is activation of the mesocorticolimbic dopamine system (Chen et al. 1991), and recent data suggest that THC can selectively increase the release of dopamine in the shell of the nucleus accumbens as do other drugs of abuse (Tanda et al. 1997).

\section{DRUG REWARD AND ALLOSTASIS}

\section{Individual Differences and Reward}

The nature of impact of the acute effects of drugs of abuse on neuronal circuits of reinforcement can contribute to the subsequent neuroadaptations that form an allostatic state in the brain reward systems. Individual differences, either via genetic or environmental factors, at critical periods may cause a predisposition to initially self-administer drugs of abuse, and a large body of evi- dence exists from an experimental approach to the study of individual vulnerability to drug reward and by extrapolation to addiction (for review, see Piazza and Le Moal 1996; Piazza et al. 1998). The fulfillment of two conditions is needed: the subjects should have equal access to the drug under identical environmental circumstances, and their biobehavioral features should be characterized before exposure to the drug. Individual differences in the propensity to develop drug intake have been demonstrated readily in the laboratory rat (Deminiere et al. 1989; Piazza et al. 1989) as well as in the propensity to manifest many other adaptive biological responses (Hooks et al. 1994a; Piazza et al. 1989, 1993).

A now classic operational design to identify individual differences is to differentiate animals on the basis of their reactivity to a stressful event (for instance their locomotor reactivity to novelty) and divide them into high reactive (HR) and low reactive (LR). The propensity of HRs to develop drug intake, compared to LRs, has been correlated with other drug-dependent responses, administered either peripherally or centrally within the mesolimbic region (Exner and Clark 1993; Hooks et al. 1991, 1992a,b,c; Piazza et al. 1989, 1991a). HR rats, independent of drug administration, show an increase of dopamine utilization in the nucleus accumbens and a decrease in the prefrontal cortex (Piazza et al. 1991b), a lower number of dopamine D2 receptors and an opposite change in D1 receptor binding (Hooks et al. 1994b). HR animals also have an increased reactivity of the stress axis.

Levels of corticosterone two hours after exposure to a stressor are positively correlated with the amount of drug consumed when it is presented for the first time to the subject (acquisition). In addition, the hormone secretion lasts longer in HRs. Finally, the levels of the stress hormone before drug administration are correlated positively with the extent of self-administration (Goeders and Guerin 1994; Piazza et al. 1991a). In summary, a vulnerable phenotype, whatever the origin, inherent and/or acquired through life experience, implies intersystemic and interrelated changes at central and peripheral levels with new drug reward set points. Recent systematic studies from different models, including history of drug intake, response to novelty, and response to stressors, have lead to the demonstration of increased drug intake across the full dose-effect function (Ahmed and Koob 1998; Deroche et al. 1997; Piazza et al. 2000; Rouge-Pont et al. 1993, 1995).

Much research has been devoted to the interactions between stress and drug intake, and there are clear interactions between stress, glucocorticoids and mesocorticolimbic dopaminergic neurons, and between dopaminergic neurons and vulnerability to drugs of abuse. Glucocorticoid receptors are localized in brain monoaminergic neurons, particularly in the ventral tegmental 
area (Härfstrand et al. 1986), and these receptors have pivotal regulatory roles in many regions of the brain (De Kloet 1991; Joels and de Kloet 1992, 1994). Direct cellular interactions between stress hormones and dopamine neurons have been difficult to document; however, glucocorticoids can interact with dopamine reward circuitry in the basal forebrain that may be independent of direct glucocorticoid/dopamine interactions. More specifically, glucocorticoids modulate the transmission of the neuropeptides dynorphin, enkephalin, tachykinin, and neurotensin, especially in the basal ganglia and nucleus accumbens (Ahima et al. 1992; Chao and McEwen 1990; Schoffelmeer et al. 1996; for review, see Angulo and McEwen 1994).

Increased corticosterone secretion or a higher sensitivity to the central effects of the hormone, either genetically present in certain individuals or induced by stress, increases the vulnerability to develop intake of drugs of abuse, and may have a role in dependence and relapse via an enhancement of the activity of mesencephalic dopaminergic neurons. Dopaminergic hyper- responsiveness in forebrain structures involved in regulation of motivation, such as the accumbens shell/ extended amygdala, is glucocorticoid-dependent (Barrot et al. 2000), but this effect is state dependent in that it varies with nutritional status and arousal status (Piazza et al. 1996b). In addition, high circulating levels of glucocorticoids can feedback to shut off the hypothalamic pituitary adrenal axis and can "sensitize" the CRF systems in the central nucleus of the amygdala known to be involved in behavioral responses to stressors (Lee et al. 1994; Schulkin et al. 1994; Shepard et al. 2000). These central CRF systems are well documented to contribute to behavioral responses to stressors (see above, Background, and Figure 2B).

CRF, when injected intracerebroventricularly, is aversive and produces place aversions (Cador et al. 1992) and taste aversions (Heinrichs et al. 1991) and raises brain stimulation reward thresholds (Macey et al. 2000). Thus, activation of brain reward systems with concomitant activation of the HPA axis ultimately can lead to activation of brain stress systems. Such an acti-
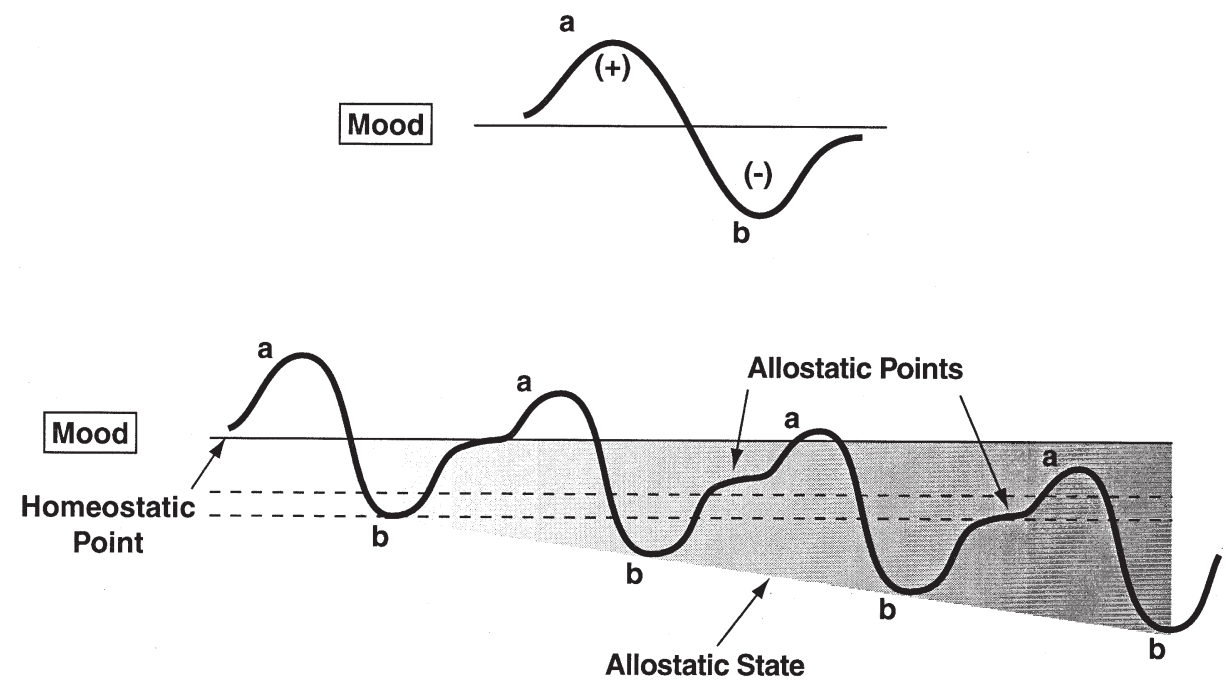

Figure 4. Diagram illustrating an extension of Solomon and Corbit's (1974) opponent-process model of motivation to incorporate the conceptual framework of this paper. Both panels represent the affective response to the presentation of a drug. (Top) This diagram represents the initial experience of a drug with no prior drug history, and the a-process represents a positive hedonic or positive mood state and the b-process represents the negative hedonic of negative mood state. The affective stimulus (state) has been argued to be a sum of both an a-process and a b-process. An individual whom experiences a positive hedonic mood state from a drug of abuse with sufficient time between re-administering the drug is hypothesized to retain the a-process. In other words, an appropriate counteradaptive opponent-process (b-process) that balances the activational process (a-process) does not lead to an allostatic state. (Bottom) The changes in the affective stimulus (state) in an individual with repeated frequent drug use that may represent a transition to an allostatic state in the brain reward systems and, by extrapolation, a transition to addiction (see text). Note that the apparent b-process never returns to the original homeostatic level before drug-taking begins again, thus creating a greater and greater allostatic state in the brain reward system. In other words, here the counteradaptive opponent-process (b-process) does not balance the activational process (aprocess) but in fact shows a residual hysteresis. While these changes are exaggerated and condensed over time in the present conceptualization, the hypothesis here is that even during post-detoxification, a period of "protracted abstinence," the reward system is still bearing allostatic changes (see text). The following definitions apply: allostasis, the process of achieving stability through change; allostatic state, a state of chronic deviation of the regulatory system from its normal (homeostatic) operating level; allostatic load, the cost to the brain and body of the deviation, accumulating over time, and reflecting in many cases pathological states and accumulation of damage. 
vation may contribute to a negative mood or state that dissipates with time, but with repeated administration of drug grows larger with time (or fails to return to normal homeostatic baseline), setting up a negative reinforcement mechanism (see also Drug Withdrawal and Allostasis) (Figure 4). Thus, glucocorticoids are involved in adaptations from homeostasis to pathophysiology in many parts of the neuraxis including the basal ganglia/extended amygdala systems, the stress axis hypophyseal systems, and cortical systems, and as such can be considered as one of the biological substrates modulating reward (Figure 2).

\section{Environmental Factors and Reward}

Environmental factors in adults, both intrinsic and extrinsic, also are important determinants of self-administration behavior, particularly during acquisition of the behavior and during reinstatement of drug-taking following extinction (Le Sage et al. 1999). Food deprivation increases drug-maintained behavior, and this generalizes to different species, routes of administration, and reinforcement schedules (De la Garza and Johanson 1987). Food restriction increases cocaine selfadministration during unlimited access to cocaine during acquisition and reinstatement (Carroll 1985; Carroll et al. 1979). Nondrug reinforcers, such as those concurrently available during acquisition and maintenance of cocaine self-administration, prevent acquisition and decrease maintenance (Carroll and Lac 1993; Carroll and Rodefer 1993; Carroll et al. 1989). Nondrug reinforcers in a clinical setting also reduce cocaine intake (Higgins et al. 1994). How these intrinsic and extrinsic factors interact with the allostatic model of addiction proposed here remains a challenge for future work.

\section{Developmental Factors and Reward}

Environmental stressful events during critical periods of development produce enduring neuroendocrinological and neurodevelopmental changes that could influence drug reward responsivity and propensity to addiction (Fride and Weinstock 1989; Henry et al. 1994; Moyer et al. 1978). Prenatal stress has been found to have long-term effects on the activity of the DA system and on DA-related behaviors (Fride and Weinstock 1989; Moyer et al. 1978). Moreover, there is evidence that prenatal stress increases and prolongs corticosterone secretion in response to stress (Henry et al. 1994).

Self-administration of stimulants has been studied in the offspring of mothers submitted to a restraining procedure during the last week of pregnancy (Deminiere et al. 1992; Maccari et al. 1991). These animals also were tested for locomotor reactivity to novelty and to stimulants, since these behaviors are characteristically enhanced in animals spontaneously predisposed to self- administration of drugs of abuse (Piazza et al. 1989). Prenatal stress animals had increased locomotor reactivity to amphetamine, particularly over the first hour of testing, and a more rapid response to amphetamine. Furthermore, prenatal stress influenced the propensity to develop amphetamine self-administration. While control and stressed animals did not differ during the first day of testing, animals in the prenatal stress group showed a higher intake of amphetamine on subsequent days.

Although the development of an organism presumably carries a strong genetic component, the organism's early environment has long-lasting influence. Both components shape psychobiological temperaments and are at the origin of individual differences. Moreover, both components can contribute equally to vulnerabilities for neurodegenerative processes and ultimately deleterious life events and can interact. Prenatal and postnatal events also modify the activity of the HPA axis (Caldji et al. 1998; Ladd et al. 2000), and maternal glucocorticoids have a major role on the development of endocrine function in the offspring. In fact, high levels of maternal glucocorticoids during prenatal stress have marked long-term repercussions on the efficiency of the offspring's HPA negative feedback mechanisms. Thus, a modification of corticosterone secretion via changes in HPA axis activity could be a biological substrate of the long-term behavioral effects of prenatal and postnatal events that could contribute to individual differences in vulnerability to allostasis in the brain reward system (see above).

\section{DRUG WITHDRAWAL AND ALLOSTASIS}

\section{Motivational Components of Withdrawal}

Motivational changes associated with acute withdrawal reflect opponent-process-like changes in the reward circuitry activated by the acute reinforcing effects of drugs of abuse. Brain systems associated with the development of motivational aspects of withdrawal are hypothesized to be a major source of potential allostatic changes that drive and maintain addiction. Acute withdrawal from the chronic use of drugs of abuse long has been associated with physical signs, and the manifestation of these physical signs varies with each drug of abuse. However, the manifestation of physical signs of withdrawal are only one of a constellation of physical and motivational symptoms associated with addiction (American Psychiatric Association 1994) and the physical symptoms of withdrawal may be largely irrelevant to the motivation to take drugs. For example, patients relapse long after physical signs of withdrawal have dissipated.

Acute withdrawal also is associated with a negative affective state including various negative emotions 
such as dysphoria, depression, irritability and anxiety. These emotional states appear to be common to withdrawal from chronic use of all major drugs of abuse and may have major motivational significance in contributing to the maintenance of drug addiction. For example, cocaine withdrawal in humans in the outpatient setting is characterized by severe depressive symptoms combined with irritability, anxiety, and anhedonia lasting several hours to several days (i.e., the "crash") and may be one of the motivating factors in the maintenance of the cocaine-dependence cycle (Gawin and Kleber 1986). Inpatient studies of cocaine withdrawal in cocaine-dependent subjects have shown similar changes in mood and anxiety states, but they generally are much less severe (Weddington et al. 1991). Opiate withdrawal is characterized by severe dysphoria, and alcohol withdrawal produces pronounced dysphoria and anxiety.

Recent studies using animal models of reward and anxiety have provided measures of behavioral changes that can be linked to emotional states associated with withdrawal from all major drugs of abuse, including opiates, psychostimulants, alcohol and nicotine. A validated measure of brain reward function is the technique of intracranial self-stimulation (Kornetsky and Bain 1990) where small amounts of electrical current to the medial forebrain bundle through an electrode will sustain vigorous behavior to obtain the stimulation. Using the technique of intracranial self-stimulation to measure reward thresholds throughout the course of drug dependence, reward thresholds are increased during withdrawal from chronic administration of all major drugs of abuse (reflecting a decrease in reward), and some of these changes can persist for up to a week post-drug (Table 2).

\section{Neural Substrates of Motivational Withdrawal}

The neural substrates and neuropharmacological mechanisms for the negative emotional-motivational effects of drug withdrawal may involve disruption of the same neural systems implicated in the positive reinforcing effects of drugs of abuse. As such, these effects may reflect changes in the activity of the same mesocorticolimbic

Table 2. Brain Reward Function During Acute Withdrawal (0-72 hours)

\begin{tabular}{lc}
\hline & Reward \\
\hline Cocaine & \\
$12-48$ hr binge & $\downarrow-\downarrow \downarrow \downarrow$ \\
Opiates & \\
$\quad$ Precipitated withdrawal & \\
$\quad$ (low to high dose naloxone) & $\downarrow-\downarrow \downarrow \downarrow$ \\
Alcohol & \\
2 weeks, $200 \mathrm{mg} \%$ & $\downarrow \downarrow \downarrow$ \\
Nicotine & \\
7 days, $9 \mathrm{mg} / \mathrm{kg} /$ day & $\downarrow \downarrow \downarrow$ \\
\hline
\end{tabular}

Table 3. Neurotransmitters Implicated in the Motivational Effects of Withdrawal from Drugs of Abuse

\begin{tabular}{ll}
\hline$\downarrow$ Dopamine & "dysphoria" \\
$\downarrow$ Opioid Peptides & pain, "dysphoria" \\
$\uparrow$ Dynorphin & "dysphoria" \\
$\downarrow$ Serotonin & pain, "dysphoria", \\
& depression \\
$\downarrow$ GABA & anxiety, panic attacks \\
$\uparrow$ Corticotropin-Releasing Factor & stress \\
$\downarrow$ Neuropeptide Y Factor & stress \\
\hline
\end{tabular}

system (midbrain-forebrain system) implicated in the positive reinforcing effects of drugs and can last up to 72 hours depending on the drug and dose administered (Legault and Wise 1994; Leith and Barrett 1976; Markou and Koob 1991, 1992; Parsons et al. 1995; Schulteis et al. 1994) (Table 2). Examples of such changes at the neurochemical level include decreases in dopaminergic and serotonergic transmission in the nucleus accumbens during drug withdrawal as measured by in vivo microdialysis (Parsons et al. 1995; Weiss et al. 1992b), increased sensitivity of opioid receptor transduction mechanisms in the nucleus accumbens during opiate withdrawal (Stinus et al. 1990), decreased GABAergic and increased NMDA glutamatergic transmission during alcohol withdrawal (Fitzgerald and Nestler 1995; Roberts et al. 1996; Weiss et al. 1996), and differential regional changes in nicotine receptor function (Collins et al. 1990; Dani and Heinemann 1996) (Table 3).

Other neurotransmitter systems not linked to the acute reinforcing effects of drugs of abuse also may be recruited to contribute to the negative emotional-motivational state associated with acute withdrawal (Koob and Bloom 1988; Koob and Le Moal 1997) (Table 3). Activation of brain and pituitary stress systems may be another common response to repeated administration of drugs of abuse that may be involved in the negative emotional state associated with acute withdrawal (Table 3). Pituitary adrenal function is activated during drug dependence and during acute withdrawal from drugs of abuse in humans. Dysregulation of the HPA axis also can persist even past acute withdrawal (Kreek 1987; Kreek et al. 1984). Corticotropin-releasing factor (CRF) function, outside of the pituitary adrenal axis, also is activated during acute withdrawal from cocaine, alcohol, opiates, and THC and thus may mediate some of the behavioral responses to stress associated with acute abstinence (Heinrichs et al. 1995; Koob et al. 1994; Richter and Weiss 1999; Rodriguez de Fonseca et al. 1997).

Rats treated repeatedly with cocaine, nicotine, THC and alcohol show significant anxiety-like responses following cessation of chronic drug administration which are reversed with intracerebroventricular administration of a CRF antagonist (Rassnick et al. 1993b; Sarnyai et al. 1995). Microinjections into the central nucleus of the amygdala of 
lower doses of the CRF antagonist also reversed the anxiogenic-like effects of alcohol withdrawal (Rassnick et al. 1993b), and similar doses of the CRF antagonist injected into the amygdala were active in reversing the aversive effects of opiate withdrawal (Heinrichs et al. 1995).

Studies using in vivo microdialysis have shown that rats withdrawn from chronic alcohol, withdrawn from chronic cocaine, and precipitously withdrawn from chronic cannabinoids show increases in the release of CRF from the central nucleus of the amygdala (Cummings et al. 1983; Merlo-Pich et al. 1995; Rodriguez de Fonseca et al. 1997). Indeed, one could speculate that the profound activation of both the HPA axis and central CRF systems during drug withdrawal, particularly after a binge, represents the ultimate activation of the HPA axis and subsequent sensitization of central CRF that cannot return to homeostatic levels (see above and Figure 3). Thus, a cascade of events could be hypothesized to develop in the following manner: 1) reward system activation in a binge; 2) downregulation of dopamine/opioid peptide systems at the end of a binge; 3) continued dysregulation of reward systems during acute withdrawal; and 4) HPA activation and central CRF activation during acute withdrawal that may persist into protracted abstinence. Thus, chronic drug self-administration sets up two major components of allostasis to the brain reward systems during a binge withdrawal cycle. There is a hypofunctioning of neurotransmitter systems involved in positive reinforcement and a recruitment of neurotransmitter systems involved in negative emotional states that provide the motivation for negative reinforcement.

Neuropeptide Y (NPY), a 36 amino acid member of the pancreatic polypeptide family, also has been implicated in the neuroadaptations associated with the development of drug addiction. NPY is abundantly present in brain areas implicated in alcohol- and drug dependence, such as the ventral striatum and amygdala (de Quidt and Emson 1986). Acute effects of NPY are remarkably similar to those of alcohol in producing a suppression of anxiety-like responses, sedation (Heilig et al. 1994), and anticonvulsant actions (Vezzani et al. 1999). A quantitative trait locus contributing to the phenotype of alcohol-preferring $\mathrm{P}$ rats has been found within a chromosomal region containing the NPY gene (Carr et al. 1998). Furthermore, in several brain areas, central expression of NPY differs between alcohol-preferring $\mathrm{P}$ and non-preferring NP rats. Among these differences are suppressed levels of NPY in the central amygdala, also seen in high alcohol drinking (HAD) rats, suggesting that NPY within this structure might play a role in the regulation of alcohol intake (Hwang et al. 1999). Furthermore, the electrophysiological response to intracerebroventricular NPY differs between P and NP rats (Ehlers et al. 1999). A causal relation between NPY expression and alcohol intake has been suggested by the inverse relationship between
NPY-expression and alcohol intake in NPY-transgenic and NPY-mutant mice, respectively (Thiele et al. 1998).

NPY also may be involved in dependence on drugs other than alcohol. NPY expression in the ventral striatum is suppressed following prolonged treatment with cocaine, possibly related to the anhedonic state present during cocaine withdrawal (Wahlestedt et al. 1991). Conversely, withdrawal from opiates is antagonized by central NPY (Woldbye et al. 1998). Overall, the role of NPY in dependence perhaps may be best viewed as an inhibitor of neuronal excitability (Palmiter et al. 1998), and it is important to note that NPY and CRF have been hypothesized to have reciprocal actions in mediating behavioral responses to stressors (Heilig et al. 1994). Thus, one may speculate that during acute withdrawal, and perhaps extended to protracted abstinence, decreases in NPY activity may accompany increases in CRF activity further potentiating the neurochemical brain stress system contribution to allostasis in the reward system.

Recruitment of nonstress, anti-reward systems involving other neurotransmitter systems also has been hypothesized to contribute to the motivational changes associated with chronic administration of drugs of abuse and may represent another contribution to the allostatic state. These include the neuropeptides dynorphin, neuropeptide FF (NPFF), and more recently orphanin FQ, and these anti-reward neurotransmitters may be natural counteradaptive mechanisms that are activated to limit impulsive behavior to limit impulsive reward-seeking behavior. Dynorphin peptides appear to decrease the dopamine activity via a presynaptic action on kappa opioid receptors in the nucleus accumbens, and kappa agonists produce aversive effects in rodents and humans (Hyman 1996). Moreover, dynorphin transmission also is modulated by glucocorticoids, and this modulation could represent an indirect action upon dopamine neurons at the terminal projection level (for review, see Angulo and McEwen 1994). Anti-opiate activities also have been hypothesized for NPFF, previously called F8Fa, based on the effects of intracerebroventricular injection of NPFFrelated peptides. Administration of NPFF attenuates morphine- and stress-induced analgesia (Kavaliers 1990), and precipitates morphine withdrawal (Malin et al. 1990). More compelling, NPFF antagonists can increase both morphine- and stress-induced analgesia, reverse morphine tolerance (Lake et al. 1992), and attenuate the naloxone-precipitated withdrawal syndrome in morphine-dependent rats. An NPFF antagonist also blocks some aspects of nicotine withdrawal (Malin et al. 1996). Anti-opiate like effects also have also been reported with administration of the orphan receptor binding peptide orphanin FQ (nociceptin) (Mogil et al. 1996), although more recent evidence suggests that orphanin FQ produces more anxiolytic-like effects (Jenck et al. 1997).

Counter-regulatory processes within the reward domain could acutely limit drug intake. In contrast, if the 
initial counter-regulatory response is inappropriate and cannot balance the activational forces involved in an allostatic response, it could lead to further drug intake and the development of allostatic-like changes in these counter-regulatory processes where the anti-reward effects develop slowly (see neuroadaptation sections and Figure 4). One could envision genetic- and environmentally based vulnerability at both ends of the counteradaptive process. Thus, these anti-reward systems are hypothesized to be abnormally activated during the development of dependence, and thus contribute to the allostatic state of reward dysfunction in addiction.

\section{EXTENDED AMYGDALA: A COMMON SUBSTRATE FOR ALLOSTATIC CHANGES IN REWARD FUNCTION}

Specific components of the basal forebrain have been identified as potential substrates for the positive reinforcing effects of drugs of abuse and the negative reinforcement associated with a state of allostasis associated with addiction. Recent neuroanatomical data and new functional observations have identified a separate entity within the basal forebrain, termed the "extended amygdala," that has been hypothesized to be a common neural circuitry for the reinforcing actions of drugs (Alheid and Heimer 1988). The term "extended amygdala" originally was described by Johnston (1923) and represents a macrostructure that is composed of several basal forebrain structures: the bed nucleus of the stria terminalis, the central medial amygdala, the area termed the sublenticular substantia innominata, and a transition zone that forms the medial posterior part of the nucleus accumbens (e.g., shell) (Heimer and Alheid 1991). These structures have similarities in morphology, immunohistochemistry and connectivity (Alheid and Heimer 1988) (Figure 3), and they receive afferent connections from limbic cortices, hippocampus, basolateral amygdala, midbrain, and lateral hypothalamus. The efferent connections from the extended amygdala include the posterior medial (sublenticular) ventral pallidum, medial ventral tegmental area, various brainstem projections, and a considerable projection to the lateral hypothalamus (Heimer et al. 1991). The observation of a major connection to the lateral hypothalamus provides an important functional link between the neurochemical/ neurobiological substrates of drug reward with the long-hypothesized neurobiological substrates of brain stimulation reward.

Specific sites within the extended amygdala and selective neurochemical and neuropharmacological actions have been identified for both the acute positive reinforcing effects of drugs of abuse and in the negative reinforcement associated with drug abstinence. Microinjections of dopamine D1 antagonists directly into the shell of the nucleus accumbens, the central nucleus of the amygdala (Caine et al. 1995) and the bed nucleus of the stria terminalis (Epping-Jordan et al. 1998) are particularly effective in blocking cocaine self-administration. In vivo microdialysis studies show a selective activation of dopaminergic transmission in the shell of the nucleus accumbens in response to acute administration of virtually all major drugs of abuse (Pontieri et al. 1995, 1996; Tanda et al. 1997). In addition, the acute reinforcing effects of alcohol are blocked by the administration of GABAergic and opioidergic competitive antagonists into the central nucleus of the amygdala (Heyser et al. 1999; Hyytia and Koob 1995), while lesions of the cell bodies within this structure markedly suppress ethanol self-administration (Moller et al. 1997).

A role for the involvement of the extended amygdala in the aversive stimulus effects of drug withdrawal includes changes in opioidergic, GABAergic and CRF neurotransmission during acute withdrawal. There is enhanced sensitivity of alcohol-dependent rats to GABA agonists during acute withdrawal (Roberts et al. 1996), and the CRF systems in the central nucleus of the amygdala are activated during acute alcohol, opioid, THC and cocaine withdrawal (Merlo-Pich et al. 1995).

These recent developments in the neurobiology of drug reinforcement combined with existing knowledge of the substrates for emotional behavior (Davis 1997) may provide critical insights to the neurobiology of the addiction process and ultimately may bridge what have been largely independent research pursuits. Perhaps more importantly, the neuronal circuit comprising the extended amygdala interacting with the brain stress axis circuit and the compulsive behavior circuit (Figure 3) are well situated to form a heuristic model for exploring the mechanisms associated with allostasis in the brain reward systems that may explain such concepts as craving and vulnerability to relapse (see above). The normal role for these counteradaptive changes observed during acute withdrawal produced by repeated drug administration may be to limit impulsive rewardseeking behavior and thus would represent homeostatic changes. However, these homeostatic changes enter the allostatic domain when they persist and are maintained and keep building during the development of dependence (see next section).

\section{VULNERABILITY TO ADDICTION AND ALLOSTASIS: NEUROADAPTATION}

\section{Sensitization and Counteradaptation}

Two neuroadaptive models (sensitization and counteradaptation) have been formulated to explain the change in reward function associated with the development of addiction or substance dependence and how this change contributes to compulsive use. Sensitization has 
been defined as the increased response to a drug that follows its repeated presentation but can take on a broader meaning when considered in the context of increased responsiveness of any drug-related phenotype (see below). Psychomotor sensitization, as defined by increased locomotor activation produced by repeated administration of a drug, is more likely to occur with intermittent exposure of drugs, whereas tolerance is more likely to occur with continuous exposure. A conceptualization of the role of psychomotor sensitization in drug dependence has been proposed where a shift in an incentive-salience state described as "wanting" was hypothesized to be progressively increased by repeated exposure to drugs of abuse (Robinson and Berridge 1993). The transition to pathologically strong wanting or craving has been proposed to define compulsive use.

An alternative counteradaptation hypothesis long has been proposed where the initial acute effect of the drug is opposed or counteracted by homeostatic changes in systems that mediate primary drug effects (Poulos and Cappell 1991; Siegel 1975; Solomon and Corbit 1974). In this opponent-process theory, tolerance and dependence are inextricably linked (Solomon and Corbit 1974), and affective states, pleasant or aversive, were hypothesized to be automatically opposed by centrally mediated mechanisms that reduce the intensity of these affective states. Opponent-process counteradaptation can be defined as a-processes (positive hedonic effects) occurring shortly after presentation of the reinforcer and showing tolerance (Figure 4). In contrast, the b-processes (negative hedonic effects) appear after the a-process has terminated, are slow to decay, and get larger with repeated exposure.

\section{Allostasis and Neuroadaptation}

The present conceptualization is an attempt to extend neuroadaptive hypotheses to the framework of allostasis. In addition, an attempt is made to integrate the psychomotor sensitization hypothesis (Robinson and Berridge 1993) and the counteradaptation hypothesis. The first important conceptualization is that the allostasis of importance to addiction is that of dysregulation of the brain reward system(s). Under such a framework of change to maintain stability, both enhanced reward and compromised reward function could contribute to an allostatic state and ultimately could potentiate the overall vulnerability to a major breakdown or dysregulation that would lead to the spiralling distress of addiction. With sensitization, empirical data support the hypothesis that the locomotor-activating effects (psychomotor sensitization) of many drugs of abuse show sensitization with repeated administration of nondependenceinducing doses (e.g., doses that do not induce physical signs of withdrawal upon abstinence). This psychomotor sensitization has been extended with certain drugs under certain situations to the reinforcing effects of drugs (Schenk and Partridge 1997) where animals with a history of drug administration initiate drug selfadministration at lower doses than drug-naive subjects. Thus, a history of drug intake could shift the dose-effect function to the left to initiate drug-seeking behavior, increase self-administration at low doses that do not normally sustain self-administration, and produce a larger neurobiological effect in an experienced subject than if given to a drug-naive subject. Generating the molecular and cellular resources necessary for increased turnover of dopamine or opioid peptide function may leave these systems vulnerable to dysregulation that contributes to the allostatic state of reward dysfunction.

Addiction, however, is associated with or even defined as (Russell 1976) a negative affective state including dysphoria, irritability, and anxiety during abstinence from a more continuous or closely spaced pattern of administration of drug, particularly as the severity of symptoms increases. This state appears to reflect a decrease in baseline reward mechanisms and an increase in drug intake to compensate for the shift in reward baseline from an opponent-process perspective.

The increase in drug intake is known classically as tolerance. In this state, more drug is required to produce an effect than in an individual not in a state of dependence. However, more recent conceptualizations in the domain of opiate/pain research have argued that tolerance in fact may be more of an "apparent tolerance" in that the b-process simply gets larger and larger requiring recruitment of more and more drug to maintain normal reward by counteracting the increasingly larger b-process (Colpaert 1996; Laulin et al. 1999). Such neuroadaptive effects may be long-lasting and are illustrated in studies regarding opiates and pain modulation. In opiate-naive rats, subcutaneous injection of heroin induces analgesia as an unconditioned immediate response, followed by allodynia and a decrease in pain threshold.

Allodynia is defined as manifestation of pain in the absence of noxious stimuli that can last several days. This phenomenon can be exaggerated by administration of the mu-opiate receptor antagonist naloxone. For example, when injected shortly after administration of a dose of morphine or fentanyl, naloxone both abolishes the acute opiate-induced increase in nociceptive threshold and also reduces it to below basal value (hyperalgesia). This hyperalgesia can be blocked by noncompetitive NMDA receptor antagonists suggesting a critical role for glutamatergic systems (Celerier et al. 1999; Larcher et al. 1998; Laulin et al. 1998). This hyperalgesia and allodynia (b-process) also sensitizes both with repeated drug administration and over time leading to an apparent tolerance. Thus, in addition to the acute unconditioned immediate response of the drug, there is recruitment of other systems such as glutamate leading 
to opposite effects that sensitize with time and additional administration of the drug. Such a neuroadaptive change has been interpreted as a form of structural memory and may be related to the same processes underlying what has been described as apparent tolerance (Colpaert 1996; Slot and Colpaert 1999). Also, acute motivational withdrawal (negative emotional state) has been observed following a single injection of morphine that gets larger following a subsequent morphine injection (Schulteis et al. 1997). While an initial hyperalgesic response simply may reflect a homeostatic change, the persistence of the overshoot (allodynia) represents more of an allostatic change. From the addiction perspective, the allostatic changes to the reward system have taken on a new dimension where to maintain normal reward function the subject must marshal substantial neurobiological resources (Figure 4).

The conundrum with such a conceptualization is how do these two neuroadaptive processes-psychomotor sensitization and counteradaptation-coexist to produce what we know as the signs and symptoms of addiction. One hypothesis is that in the early stages of compulsive drug-taking, where negative affect postdrug is minimal and the subject appears driven mainly by the positive reinforcing effects of a drug or anticipation of the positive reinforcing effects of the drug, psychomotor sensitization plays an important role. Here, drug-seeking is driven by positive reinforcement and resembles more a classical impulse control disorder. Sensitization may be involved in the preoccupation/anticipation stage during acquisition of drug-taking and may be recruited again during reinstatement of drugtaking following detoxification and prolonged abstinence (Koob and Le Moal 1997).

Impulsivity, in the context of impulse control disorders, has been defined as when an individual feels an increasing sense of tension or arousal before committing an act and then experiences pleasure, gratification or relief at the time of committing an act (American Psychiatric Association 1994). One prediction such a formulation would make is that before or during the early stages of transition to addiction, repeated administration of drugs at doses that do not produce negative affective states upon cessation of drug intake are more likely to manifest psychomotor sensitization. Psychomotor sensitization, in turn, could enhance drug intake by incentive motivational (salience) processes rather than tolerance or apparent tolerance. However, when negative affective states (b-processes) begin to grow during the course of more and more drug-taking, the counteradaptation mechanisms may begin to predominate with tolerance or "apparent tolerance" to the reinforcing effects and manifestation of affective withdrawal. Interestingly, from the perspective of a broad definition of the sensitization process, an allostatic-like change in negative affective states which gets larger with repeated exposure to the drug also represents a true "sensitization" (Figure 4). This would lead to addiction being driven by negative reinforcement, and here the addiction cycle takes on characteristics more of a compulsive disorder where the addiction cycle presumably recruits the same neural circuits associated with a compulsive disorder (cortico-striatal-thalamic loop) (Figure 3). Compulsion is defined in this context as when an individual performs repetitive behaviors, the goal of which is to prevent or reduce anxiety or distress, not to provide pleasure or gratification (American Psychiatric Association 1994).

\section{Neurosubstrates of Allostatic Neuroadaptation}

Thus, sensitization as a process may have a more general role in the development of allostasis in the reward system that accompanies the transition to addiction. First, dopamine and glucocorticoids participate in a "sensitized" (psychomotor sensitization) response to a history of drug intake as measured by locomotor activation and drug threshold for initiating drug selfadministration. Second, the negative affective state becomes "sensitized" (negative affective state sensitization) and grows larger with repeated administration of drug, recruiting not only more brain circuits but also additional brain neurochemical systems such as the brain stress systems (Figures 4 and 5). The combination of a recruited brain stress system and an already compromised reward circuit (as reflected in "depletion" or "dysfunction" in the dopamine, opioid peptide, and even serotonergic domains) provides an additional powerful contribution to the negative affective state that reflects the allostatic state of reward system dysfunction.

Both of these theoretical positions would allow one to predict neuroadaptation at the molecular, cellular and system levels. Neurochemical changes that are altered during the development of sensitization have been hypothesized to involve the same neurotransmitters implicated in the acute reinforcing effects of drugs (Koob and Bloom 1988). For example, sensitization to psychostimulants is associated with a number of neurochemical changes within the mesolimbic dopamine system (White 1996). These include subsensitivity of dopamine autoreceptors in the ventral tegmental area, a supersensitivity of D1-mediated responses (Henry and White 1991), increased levels of adenylyl cyclase and protein kinase A, and decreased levels of Gi proteins (Nestler 1996; Self and Nestler 1995). In addition, there is cross-sensitization to stressors, and elevated glucocorticoids are associated with a propensity to selfadminister doses of drugs that are not usually reinforcing (Piazza and Le Moal 1996; Piazza et al. 1996a).

At the molecular level, there is a decrease in the ability of cocaine to induce the intermediate early gene $c-f o s$ 


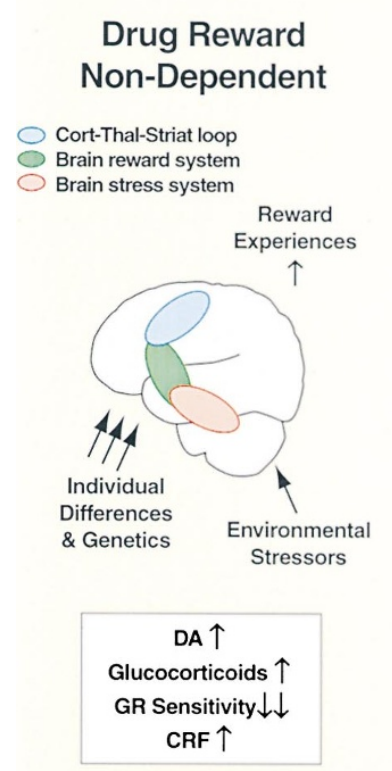

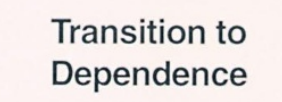
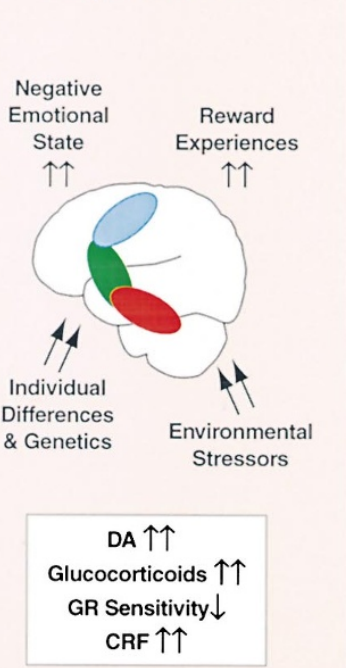

\section{Addiction}

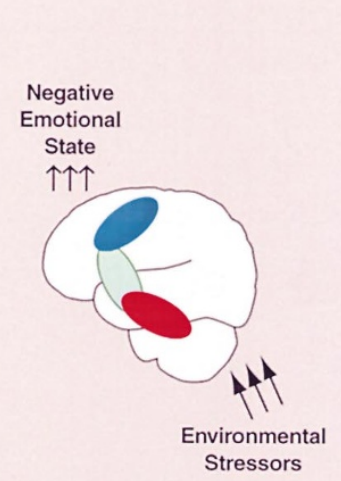
DA $\downarrow \downarrow$
GR Sensitivity $\uparrow$ ? CRF $\uparrow \uparrow \uparrow$

Protracted

Abstinence

\section{Allostasis}

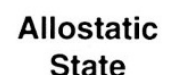

State

\section{Allostatic Load \\ (Pathology)}

Figure 5. Diagram depicting the relationship between the continuum from allostasis to pathology and the transition from drug-taking to addiction to protracted abstinence. Three simplified brain circuits are conceptualized to change and contribute to the allostatic state in the brain reward system: the reward system itself (green), the brain stress systems (red), and the cortico-thalamic-striatal (CTS) loop (blue). In the nondependent state, environmental stressors are minimal, reward experiences are normal, and the brain stress and CTS loop are not engaged. During the transition to dependence all three circuits are engaged, and in the state known as addiction, the brain reward system is in a major underactivated state while both the brain stress system and the CTS loop are highly activated. Protracted abstinence is characterized by a return toward a normal state but with residual activation of the brain stress systems and residual underactivation of the brain reward system. Note that activation of the hypothalamic pituitary adrenal axis is hypothesized to drive the brain stress axis to contribute to the allostatic state of addiction. DA, dopamine; CRF, corticotropin-releasing factor; GR, glucocorticoid receptor. The following definitions apply: allostasis, the process of achieving stability through change; allostatic state, a state of chronic deviation of the regulatory system from its normal (homeostatic) operating level; allostatic load, the cost to the brain and body of the deviation, accumulating over time, and reflecting in many cases pathological states and accumulation of damage.

but a sustained expression of the AP-1 transcription factor (Self and Nestler 1995). In addition, recent evidence suggests that novel isoforms of delta-FosB, a member of the Fos family of transcription factors, accumulate in specific regions of the brain in response to repeated administration of drugs of abuse and other psychoactive drugs (Nestler et al. 1999). Particularly intriguing is evidence provided by inducible transgenic mice upon overexpression of delta-FosB showing biochemical and behavioral changes which mimic the chronic drugtreated state (Nestler et al. 1999). Chronic administration of other major drugs of abuse such as opiates and alcohol produce similar molecular changes in second messenger, signal transduction pathways and transcription factors (Koob et al. 1998b). Thus, the sensitization associated with locomotor activation and the mesolimbic dopamine system involves neuroadaptations that can be long-lasting and contribute to drug-seeking. Unknown at this time is whether these molecular adap- tations persist into the counteradaptation stage where other neurochemical systems are recruited.

Overactivity in the brain reward system produced by excessive drug-taking is hypothesized to engage the after-effects of allostatic adaptations in an attempt to maintain functional hedonic states. The functional state of neurotransmitter systems activated to produce drug reward ultimately may be depleted or unable to keep up with the demand involved in mediating the acute reinforcing effects of drugs of abuse. Examples of such allostatic adaptive neurochemical events might include decreases in dopaminergic and serotonergic transmission in the nucleus accumbens during drug withdrawal as measured by in vivo microdialysis (Parsons et al. 1995; Weiss et al. 1992b), increased sensitivity of opioid receptor function in the nucleus accumbens during opiate withdrawal (Stinus et al. 1990), decreased GABAergic and increased NMDA glutamatergic transmission presumably in the accumbens-amygdala reward circuit 
during alcohol withdrawal (Fitzgerald and Nestler 1995; Roberts et al. 1996; Weiss et al., 1996), and differential regional changes (reward system versus nonreward systems) in nicotine receptor function during nicotine addiction (Collins et al. 1990; Dani and Heinemann 1996).

\section{Allostatic Neuroadaptation and the Stress Axis}

Such allostatic adaptations also may involve the recruitment of neurotransmitters that mediate behavioral and physiological responses to stressors. Neurochemical components of stress responses that appear to be changed during acute withdrawal from alcohol, cocaine, THC or opiates are increases in CRF systems and decreases in NPY systems, and thus may mediate aspects of stress associated with abstinence (Koob et al. 1994). These effects have been hypothesized to involve an action on CRF systems in limbic areas implicated in behavioral responses to stressors (Koob et al. 1994), but also may include activation of the hypothalamic pituitary adrenal axis (Kreek and Koob 1998; Piazza and Le Moal 1996). Dysregulation of the HPA axis has important functional consequences that range from activating the brain reward system, to serving as a stimulus for self-medication, to actual neurotoxicity (Kreek and Koob 1998). Activation of the HPA axis also may in turn "sensitize" the limbic neurotropic stress systems that may contribute to the negative affective state of the addiction cycle and set up an important source of negative reinforcement (e.g., self-administration of a drug such as alcohol to suppress an overactive limbic CRF system; see above) (Schulkin et al. 1994; Shepard et al. 2000).

Norepinephrine systems emanating from the nucleus locus coeruleus also long have been hypothesized to be involved in mediating behavioral constructs associated with alertness, arousal and stress. Central nervous system norepinephrine systems have been considered as having a role in arousal/alerting functions (Robbins and Everitt 1995). Stress increases the turnover of norepinephrine in many terminal projection areas of the locus coeruleus (Korf et al. 1973) and increases extracellular norepinephrine in the hippocampus (Abercrombie et al. 1988), and a variety of stressors increase the discharge rate of locus coeruleus neurons (Valentino et al. 1993).

A number of brain sites currently hypothesized to be particularly important for the behavioral effects of CRF, specifically with regard to the role of CRF in arousal and behavioral responses to stress, are closely linked to the brain norepinephrine systems including the locus coeruleus, the paraventricular nucleus of the hypothalamus, the bed nucleus of the stria terminalis, and the central nucleus of the amygdala (Valentino et al. 1993; Van Bockstaele et al. 1998). Thus, stress, either autonomic or emotional, activates CRF release in the nucleus locus coeruleus which in turn stimulates activ- ity in the locus coeruleus. This activation of the locus coeruleus in turn produces release of norepinephrine in forebrain terminal projections. Particularly intriguing are the data suggesting that norepinephrine in these terminal areas in turn stimulates the release of CRF (for example, in the paraventricular nucleus of the hypothalamus, the bed nucleus of the stria terminalis, and the central nucleus of the amygdala). These are brain structures with a high density of CRF-containing cell bodies and terminals and are well-implicated in mediating the role of CRF in behavioral responses to stress.

Finally, the evidence that CRF originating from these noradrenergic terminal areas also innervates the region of the locus coeruleus (Van Bockstaele et al. 1998) suggests a potentially powerful feed-forward system (Koob 1999a). Such a feed-forward system may be a mechanism for the progressive augmentation of stress responsivity with repeated exposure. Conceptualized as stress syndrome dysregulation (Chrousos and Gold 1992), kindling (Post and Weiss 1995), or a change in allostatic set point (Schulkin et al. 1998), a feed-forward system involving CRF/norepinephrine interactions could be hypothesized to be a potential additional stress mechanism contributing to the allostasis during the development of addiction. A challenge for future studies will be to revisit the role of brain norepinephrine systems in drug addiction in the context of allostatic changes in arousal and stress, particularly with such drugs as alcohol and opiates where withdrawal is associated with a dramatic activation of the sympathetic nervous system.

\section{Allostatic Neuroadaptation and Drug Reward Set Point}

Support for an allostatic view of reward regulation comes from increasing evidence that chronic exposure to drugs of abuse can change the "set point" for drug reward. Animals with prolonged access to cocaine or heroin will continue to increase their cocaine intake on a daily basis and show enhanced intake of cocaine at all doses tested (Ahmed and Koob 1997, 1998, 1999; Ahmed et al. 2000). Indeed, the dose-effect function appears to shift upward instead of to the right (tolerance) or to the left (sensitization) (Ahmed and Koob 1998). Animals with a history of alcohol dependence show prolonged increases in alcohol self-administration long past acute withdrawal (Roberts et al. 2000a). Such changes in drug reward set point may reflect an allostatic change rather than simply sensitization or homeostatic adaptation. This same phenomenon has been demonstrated in animals selected on the basis of their inherent differential vulnerability to drugs (Piazza et al. 2000; Sutton et al. 2000).

The allostatic changes set in motion by a history of 
drug use may begin with sensitization and the overactivation of the mesolimbic dopamine system described above which may in part be driven by an activation of the hypothalamic pituitary adrenal axis. This in turn drives further drug use, which depletes reward transmission, but also recruits brain stress systems to counteract the increased hedonic processing. The combination of high dopamine turnover (example of driving positive reward) in the face of high CRF activity (recruited antireward), and possible low NPY activity, leads to a severe allostatic state in the brain reward system should the drug become unavailable (Figures 3 and 5).

\section{VULNERABILITY TO ADDICTION AND ALLOSTASIS: GENETIC CONTRIBUTIONS}

\section{Human Genetic Studies}

Genetic influences on human substance abuse vulnerability have been documented by using classical and molecular genetic approaches. More recently, research to find specific genes contributing to human vulnerability is being developed in parallel with studies in experimental animal models in order to define the limits of possible genetic and environmental factors in vulnerability (Cadoret et al. 1986; Devor and Cloninger 1989; George and Goldberg 1989; Uhl et al. 1995). From clinical and naturalistic approaches, it is generally agreed that preexisting intrinsic vulnerability does exist that leads from recreational use to abuse and dependence for a small percentage of users (Anthony et al. 1994). Why some individuals succumb and others do not is not a trivial question, but it has been generally neglected despite clinical evidence. Genetic interactions with compulsive drug use may be explained by an individual differences-centered approach to the problem. Here, abuse is the consequence of a peculiar, possibly pathological reaction to the drug, and individuals are vulnerable because of an intrinsic functional brain state that interacts with the drug.

Clinical epidemiological studies, and more recently experimental studies, have shown that individual vulnerability to drug abuse is not simply a drug-specific phenomenon. If drug abuse was only a drug-specific phenomenon, then drug-vulnerable subjects would differ from drug-resistant ones only for specific drug-induced behaviors and would not show any other psychobiological perturbations. In fact, vulnerability to drug addiction may involve certain personality characteristics, sometimes in the context of comorbidity with other psychopathological disorders. In other words, such vulnerability - whatever the cause, genetic and/ or environmental life events - may reflect a potential or already constituted state of reward system allostasis. Such vulnerability may be a drug-specific phenomenon in that a large component of the heritability is specific for a particular drug (Bierut et al. 1998; Merikangas et al. 1998).

Substantial evidence exists for an important genetic contribution to the vulnerability to develop alcoholism and tobacco addiction. Twin studies with adoption have provided strong evidence for an important genetic influence on the risk of becoming an alcoholic in both men and women (Heath et al. 1997a). Twin studies in Scandinavia and the United States have shown consistently higher rates of alcoholism in monozygotic compared to dizygotic twins of male alcoholics (Hrubec and Omenn 1981; Kaij 1960; Koskenvuo et al. 1984), and adoption studies have shown consistently higher rates of alcoholism in the adopted-away sons of alcoholic biological parents than in control adoptees (Cadoret et al. 1994; Goodwin et al. 1973). While a genetic influence on alcoholism in women generally has been considered weaker, recent analyses suggest that this may be the result of low statistical power due to the low base rate of alcoholism in women (Heath et al. 1997b; Kessler et al. 1994).

The biological bases for such genetic contributions are largely unknown, but a number of avenues have been suggested by studies of high risk individuals. Alcohol challenge research suggests a genetic contribution to differences in sensitivity to alcohol with sons of alcoholics showing less of a response to alcohol in such measures as body sway, subjective measures of intoxication (self-rated), and electrophysiological measures (Schuckit 1994). Impulsivity, behavioral undercontrol and negative affectivity also have been identified as potential mediators of the genetic contribution to alcoholism in prospective studies (Sher 1991).

Recent evidence also suggests that genetic factors have an important influence on the onset and development of tobacco smoking (Heath and Madden 1998). Using twin data and a logistic regression model approach, data suggest that in men genetic factors play an important role in predicting which individuals who become cigarette smokers progress to longterm persistent smoking (Heath and Madden 1998). For example, using multiple logistic regression analyses predicting persistence in smoking among smokers, the odds ratios are significantly higher for monozygotic twins than for dizygotic twins (Heath and Madden 1998). Similar conclusions have been drawn using a genetic liability model approach with monozygotic and dizygotic twins (True et al. 1997).

One untested hypothesis is that individuals at risk for drug abuse in fact have a biological vulnerability within the same domains as those biological changes hypothesized to develop over the course of heavy drug intake regardless of genetic history (see above). In the study of the genetics of alcoholism, there is evidence of genetic control over various aspects of drinking but to a modest degree for any one dimension. This suggests 
that both environmental factors and environmentgenetic interactions may play a role (Sher 1991).

\section{Animal Genetic Studies}

Animal studies have established a number of models of various aspects of alcoholism including excessive drinking through the use of inbred strains and selective breeding programs (Crabbe 1989; Crabbe et al. 1999). The animals selectively bred for excessive drinking show many of the characteristics of human alcoholics such as high alcohol intake, a generalized decreased sensitivity to alcohol, and drinking to the point of showing withdrawal effects upon cessation of drinking (McBride and Li 1998). Studies with inbred strains of mice allow for crossing and the identification of specific gene loci linked to a given trait by use of quantitative trait locus analysis (Phillips et al. 1994). Both approaches have begun to identify neurobiological substrates that may be responsible for excessive drinking including in the selectively bred animals alterations in dopaminergic and serotonergic function and in the inbred mouse strains identification of gene loci associated with specific neurotransmitters such as GABA and NPY (Carr et al. 1998; Crabbe et al. 1999; Li 2000). Parallel studies have yet to be performed with other drugs of abuse. However, there are major differences in the avidity with which inbred strains of mice will self-administer drugs that could provide the basis for future genetic studies of vulnerability to addiction or even protection from drug-seeking. For example, the BALBc mouse will not self-administer cocaine but if pretreated with an anti-anxiety drug such as diazepam will avidly self-administer cocaine (David et al. 2000). These results suggest that in these animals the acute anxiogenic- or stress-like actions of cocaine protect against self-administration.

Thus, genetic factors can act as constitutive (trait) mechanisms in the organism to produce the differential sensitivity within the brain reward and stress systems that can interact with environmental factors to produce a greater or lesser state of allostasis within the brain reward system upon drug-taking. Decreased sensitivity to a drug, including sensitivity to the initial aversive effects of a drug, can lead to increased drug intake which can set up further challenges to the reward circuits and interacting neural systems (Figure 5). However, although largely neglected to date in genetic studies, one also can envision differential sensitivity to the sensitization of negative affective state or stress associated with removal of chronic administration of drugs, even independent of initial sensitivity to the drug or initial avidity for the drug. Clearly, the combination of all three factors-an initial high avidity for the drug, decreased sensitivity to the drug's initial aversive effects and increased sensitivity to the untoward consequences to the brain reward system of removal of chronic administration of the drug-would be a powerful contribution to vulnerability to addiction.

\section{VULNERABILITY TO ADDICTION AND ALLOSTASIS: NEUROBIOLOGICAL MECHANISMS}

\section{Opponent-Process Counteradaptation in Vulnerability to Addiction}

The brain reward system presumably evolved to provide a motivational mechanism for survival and propagation of the species (Nesse and Berridge 1997; Panksepp 1998; Stellar and Stellar 1985; Toates 1990). Rewards in the natural environment generally are associated with the seeking of nourishment, shelter and preservation of the species (i.e., reproduction). One can speculate that the basic mechanisms involved in reward regulation are the same mechanisms usurped by drugs of abuse. It follows then that the neuroadaptations in the brain reward system associated with an abundance of rewards produced by changes in the environment are the same neuroadaptations observed to drug rewards. As such, drugs of abuse have powerful neuropharmacological effects that may short circuit the neurochemistry of reward.

Using a conceptualization originally grounded in opponent-process theory (Solomon and Corbit 1974), the effects of natural rewards on hedonic state are dependent on the nature of the reward and the frequency of delivery (Figure 4). Rewards that have initial pleasurable effects can show some apparent tolerance and some evidence of a negative affective opponent-process. In contrast, rewards that have initial aversive effects can show tolerance to the aversive effects, a gradual increase in the positive affective opponent-process, and then subsequently a second opponent-process that may represent yet another negative affective state. Evidence for allostasis to the point of addiction with natural rewards is controversial, but compulsive behavior with impairment in social and occupational functioning has been observed with such events as gambling, shopping, exercise, eating, sex, and computer use (Baumeister et al. 1994; Orford 1985). With the possible exception of gambling and perhaps certain eating disorders, the intensity and frequency of such disorders is less than that of drug addiction. A challenge for future research will be to understand whether such nondrug pathology has the same neurochemical underpinnings as drug addiction and produces a state of allostasis in the brain reward system that predisposes to drug addiction.

As described above, in drug addiction itself, the evidence for neuroadaptations to the reward system is overwhelming and can produce profound changes in reward set point (Figure 4). Here, again grounded in opponent-process theory, drugs are conceptualized to 
have dramatic effects on hedonic processing that are time and drug dependent. Closely spaced administration of powerful reinforcing drugs can produce "apparent" tolerance to the initial rewarding effects and a pronounced "sensitization" of the negative affective state. This negative affective state is conceptualized to grow over time until the subject in effect simply is trying to return to a normal hedonic level (Kissin and Gross 1968) (Figure 4). Translated to the situation of the drug addict, the addict's reward system must work harder and harder to stay in the same place. Thus, in an allostatic view, stability is purchased at the cost of increased resources and decreased margin of error or reserve (B. Carroll, personal communication). This contrasts with a cost-neutral means of maintaining stability which characterizes homeostasis. The allostatic state conceptualized here is comprised of the residual neurochemical changes that may or may not be manifested as a behavioral phenotype but provide a biological transformation or "brain signature" that may be long lasting and involve neurobiological domains from motivation to memory.

Allostasis in the reward system can be the result of chronic drug administration (Figure 5) but also may result from a history of environmental insult that falls into the realm of stress. Both perinatal and developmental stressors can contribute to the vulnerability of the brain and pituitary stress systems (Caldji et al. 1998; Ladd et al. 2000), and such a vulnerability may impact directly on negative affective states that contribute to reward system allostasis. One also could imagine that particular experiences with nondrug rewards could interact with the same neurobiological substrates. Clearly, there appears to be a relationship between noveltyseeking, antisocial personality disorder, impulsivity and drug addiction (see above). Alternatively, impulse control per se may be a separate dimension which interacts with motivational states. Whether these disorders have some related or common neurochemical substrate with addiction remains to be determined.

\section{Neurobiological Mechanisms in Vulnerability to Addiction}

The neurobiological systems hypothesized to be responsible for the allostatic state of the reward system by the transition to addiction and the continuation and maintenance of addiction derive from multiple sources. First, the neurotransmitter systems involved in the acute reinforcing effects of drugs of abuse, such as dopamine, serotonin, opioid peptides, GABA and glutamate, are hypo-functional (see above). Second, the neurotransmitter systems associated with anti-reward and stress may be recruited to contribute to the state of allostasis in the reward system (see above). The hypothesis proposed here is that transmitter function involved in the acute reinforcing effects of drugs of abuse is compromised with the establishment of drug dependence (Figure 5, green) and that neurotransmitter function associated with anti-reward and stress (Figure 5, red), and the "compulsive" circuit of the cortico-striatalthalamic loop (Figure 5, blue), are recruited during the development of drug dependence (Figure 5).

A subhypothesis is that the core circuitry involved in the adaptations that form the state of allostasis in the reward system can be localized to elements of the extended amygdala, in particular the central nucleus of the amygdala, the bed nucleus of the stria terminalis, and the transition zone in the posterior shell region of the nucleus accumbens. Later, as allostasis continues to develop, it grows by recruitment of additional perturbed systems: an overactive brain stress system and an overactive compulsive behavior circuit. The allostatic state actually may pass into overt neural pathology as hypothesized for the role of cortical damage in the development of alcoholism (Crews 1999). Neurotoxicity to the prefrontal cortex from high alcohol exposure has been hypothesized to contribute to disruption of executive function and consequent perseveration that could be an extension of dysfunction of the compulsive circuit of the cortico-striatal-thalamic loop (Crews 1999).

A particular challenge for future research is to determine how cellular and molecular perturbations produced by chronic administration of drugs of abuse lead to the major changes in neurobiological systems outlined above. Data to date suggest that there are multiple molecular/cellular changes in brain neuronal systems produced by chronic administration of drugs of abuse. Noteworthy effects that appear common to many or all drugs of abuse with chronic administration are activation of glucocorticoid neuromodulatory systems in the nucleus accumbens and/or ventral tegmental area (Barrot et al. 2000; Piazza and Le Moal 1996, 1997), subsensitivity of dopamine autoreceptors in the ventral tegmental area (White 1996), hypersensitivity of dopamine D1 receptor-mediated responses in the nucleus accumbens, increases in adenylyl cyclase activity, increases in protein kinase activity, increases in phosphorylation in the nucleus accumbens, and induction of transcription factors in the nucleus accumbens (Koob et al. 1998b; Nestler and Aghajanian 1997). While dysregulation of dopamine function can be linked to some of these cellular/molecular changes, in models even as well defined as psychomotor sensitization, the phenotypic manifestation of the behavioral response does not always correspond to the cellular/molecular mechanisms hypothesized. This suggests that there may be subtle underlying contributions to the phenotype that are as yet undiscovered, and that the precise nature of cellular/molecular changes underlying allostasis in the reward system remain to be uncovered. 


\section{DRUG RELAPSE AND ALLOSTASIS}

Drug addiction is a chronic relapsing disorder characterized by cycles of drug abuse, abstinence and repeated attempts to stop. The vulnerability for relapse is poorly understood but clearly involves multiple factors such as drug availability, conditioning factors and stress, and hypothetically can be driven by a residual "brain signature" in any one of the three circuits dysregulated during the addiction cycle (see Figures 4 and 5). The majority of relapses occur during states of stress (Marlatt and Gordon 1985) or situations with high drug cue or drug availability (Marlatt and Gordon 1985). Behavioral treatments have been traditionally viewed as effective in helping prevent relapse and a limited number of effective pharmacological treatments have proven effective in preventing relapse (Mason and Ownby 2000; Mason et al. 1999; Project MATCH Research Group 1997).

Embedded in the construct of vulnerability to relapse is another construct termed protracted abstinence which can be defined as a subtle state of residual abstinence after acute withdrawal. While originally defined in the context of physical symptoms associated with abstinence, the present conceptualization refers to a residual allostatic state within the brain reward system (Figure 5, green). It is important to emphasize that protracted abstinence can contribute to a vulnerability to relapse by a state change as opposed to a change in perception of any given stimulus. For example, a priming-like activation by a conditioned positive reinforcer in the context of high-circulating stress steroids superimposed upon an activated brain stress neurotransmitter system (Figure 5, red) may be a very powerful impetus for relapse (see below).

\section{Stress Hormones, Dopamine and Vulnerability to Relapse}

As established above, the relationship between stress and dopamine is to a large extent mediated by corticosterone (dopamine, stress, and stress hormones are elements of a pathophysiological chain of events and thus at the basis of various vulnerabilities, drug sensitivity included) (McEwen 1998b; Piazza et al. 1996a). Stress hormones are highly lipophilic and enter into the brain where they are ubiquitously distributed to two families of receptors. These cytosolic receptors, while activated by the hormone, are translocated toward the nucleus and bind to DNA at specific regulatory genes to modulate their expression. The Type I mineralocorticoid receptors have a high affinity for corticosterone or cortisol and are concentrated mainly in limbic regions - the septum, amygdala and hippocampus. They have been shown to play a role in the modulation of responses to environmental and emotional stimuli and in the modulation of the stress axis. They modulate basal cortisol levels, circadian rhythms and hippocampal inhibition of the HPA axis (fast feedback) (Figure 2A).

The Type II glucocorticoid receptors have a lower affinity for corticosterone and are widely distributed with high density in the hypothalamus, on CRF and proopiomelanocortin (POMC) neurons, and also in the amygdala and hippocampus. They have been shown to regulate the genes involved in CRF and POMC secretion. They terminate the stress HPA response and are active in the delayed feedback regulation induced by glucocorticoids (Albeck et al. 1994).

As a biological participant in the state of stress, stress hormones interact with limbic and cortical regions and regulate CRF-sympathetic systems (Figure 2). Such stress hormones, via alterations of neuronal activity, consequently can induce neurobehavioral pathology. As noted above, dopaminergic neurons have receptors for glucocorticoids (Härfstrand et al. 1986), and increases in the circulating levels of the hormones induce an increase of dopamine utilization in mesocorticolimbic neurons, an effect that is state-dependent (i.e., higher during the dark phase, or during food intake) (Piazza and Le Moal 1997). Thus, increases in corticosteroids renders animals more vulnerable to the acute reinforcing effects of drugs of abuse (Piazza and Le Moal 1997). Moreover, the hormones have by themselves reinforcing properties, both orally or intravenously at very high levels similar to those triggered by stressful situations (Piazza et al. 1993). These stress hormones also elevate CRF gene expression in limbic regions and participate in anxiety, dysregulation of affective states, and chronic anticipatory angst (Chrousos and Gold 1992; Johnson et al. 1992). Thus, stress hormones, by actions on dopamine neurons and on brain regions involved in drug actions, are directly involved in the dysregulation of reinforcement and globally involved in the development of dependence (Piazza and Le Moal 1996).

Dysregulation of hypothalamic pituitary adrenal responsiveness may be a common element associated with protracted abstinence and vulnerability to relapse. In alcoholism, compromised HPA function has been demonstrated in actively drinking alcoholics and persists long after alcoholics cease alcohol consumption and includes blunted ACTH and/or cortisol responses to CRF or stress (Adinoff et al. 1990). In addition, nonalcoholic subjects with a family history of alcoholism have abnormally blunted HPA responses to CRF (Waltman et al. 1994). Animal studies have revealed that chronic administration of alcohol produces a decrease in anterior pituitary POMC mRNA concentrations weeks after withdrawal and led to the hypothesis that increased alcohol intake vulnerability may result from a dysregulation of the HPA axis (D. Rasmussen, personal communication). In heroin and cocaine addiction, both drug-free former heroin addicts and former cocaine addicts have shown hyperresponsivity to the metyrapone 
challenge test with excessive levels of ACTH released in response to the abrupt cutoff of the cortisol feedback at the level of the pituitary and hypothalamus (Kreek 1987, 1992; Kreek et al 1984; Schluger et al. 1997). Whether such hyperresponsivity applies also to stressor challenges remains to be determined. Since, as described above, activation of the HPA axis can "drive" (e.g., activate) central extrahypothalamic CRF systems, such an activation of both brain and hormonal stress systems could contribute to a residual negative affective state and could be a powerful impetus for relapse.

\section{Brain Stress Systems and Vulnerability to Relapse}

Central nervous system stress systems also may be engaged during the development of drug dependence (see above), and residual changes in the activity of such brain stress systems during protracted abstinence may contribute to vulnerability to relapse (Figure 5, red). CRF and norepinephrine activity in ascending noradrenergic systems have been shown to be activated, while NPY systems may be inactivated, during acute withdrawal from most drugs of abuse (Aston-Jones and Druhan 1999; Koob 1999a). CRF antagonists have been shown to block stress-induced reinstatement of drugseeking behavior in rats extinguished from intravenous self-administration (Shaham et al. 1998). Even more compelling is the evidence suggesting that during protracted abstinence from alcohol, CRF antagonists show efficacy in rats with a history of dependence (A.J. Roberts, personal communication). Also, one hypothesis to explain the increased drinking in NPY knockout mice and alcohol-preferring rats is drinking to suppress a compensatory increase in a brain stress system such as CRF (Richter et al. 2000; Thiele et al. 1998). How the combined dysregulation of circulating corticosteroids and central nervous system CRF and NPY systems interact during protracted abstinence to different drugs of abuse contribute to allostasis and increase vulnerability to relapse remains a challenge for future studies.

As noted above, relapse to drug-seeking in subjects with a history of addiction can be triggered by many factors such as stress, psychiatric comorbidity and psychosocial factors (Figure 5, blue). In the domain of psychosocial factors, conditioned responses to drug-related stimuli have been hypothesized to play an important role in triggering a state of "craving" and in initiating relapse. Animal models of such conditioned phenomena have centered on stimuli associated with drug-taking and a number of self-administration situations. Animals can be trained to self-administer a drug, and when drug delivery is paired with a previously neutral stimulus which can come to predict drug availability, animals can be trained in second-order schedules to work for a previously neutral stimulus that ultimately predicts drug availability. Using conditioned place prefer- ence, previously neutral stimuli (specific location) can be paired with drug administration and the animals can be tested for preference for the paired stimulus. Studies using these models have begun to establish a neurobiological substrate and the neuropharmacological components of such conditioned effects.

Conditioned reinforcement in general, and for drugs of abuse in particular, has been hypothesized to be integrated within the ventral striatum through convergent interactions with the amygdala (Everitt et al. 1999). Lesions of the basolateral amygdala block the development of conditioned reinforcement in a variety of paradigms including an operant procedure where animals must learn a new task to obtain a previously neutral stimulus paired with a primary reinforcer (Burns et al. 1993), conditioned place preference (Hiroi and White 1991), and a second-order schedule of cocaine self-administration (Whitelaw et al. 1996). Basolateral amygdala lesions also block the development of conditioned withdrawal in rats (Schulteis et al. 2000). In contrast, the ventral subiculum appears to mediate the potentiation of locomotor activation and conditioned reinforcement by stimulant drugs but does not mediate informational aspects of the conditioned reinforcement process (Everitt et al. 1999).

In a series of elegant studies extending this dichotomy to the projections of the basolateral amygdala and ventral subiculum it appears that excitotoxic lesions of the shell of the nucleus accumbens block the potentiation of conditioned reinforcement by stimulant drugs, similar to ventral subiculum lesions, but do not block the control over the instrumental behavior by the conditioned reinforcer (Cador et al. 1989; Parkinson et al. 1999), whereas excitotoxic lesions of the core of the nucleus accumbens produce effects similar to basolateral amygdala lesions (Parkinson et al. 1999). Consistent with these animal models, brain imaging studies in humans have shown that cue-induced cocaine craving is associated with activation of the amygdala and anterior cingulate cortex (Childress et al. 1999; Maas et al. 1998). The neurochemical substrates underlying such conditioned reinforcement effects are under intense investigation but have been hypothesized to involve glutamatergic afferents from the basolateral amygdala and ventral subiculum (Everitt et al. 1999) as well as dopaminergic projections to the basolateral amygdala and other cortical areas (Berke and Hyman 2000). Low doses of dopaminergic antagonists can block the conditioned responding produced by a cocaine cue (Weissenborn et al. 1996) and a D3 partial agonist-attenuated responding for the stimulus predicting cocaine reinforcement in a second-order schedule (Pilla et al. 1999). However, acquisition of responding as a measure of conditioned reinforcement is unaltered by dopaminergic blockade suggesting that the dopaminergic component is the activation of responding for the conditioned reinforcement, not the informational content of the stimuli. 
The implications of understanding the neurocircuitry of conditioned reinforcement for an allostatic view of addiction is that these pathways can provide the information necessary to activate primary reward circuits that may already be in a state of dysregulation. Recent emphasis has been placed on the role of "memory" in drug craving (Berke and Hyman 2000). Others have argued that increased mesolimbic dopamine release may identify novel stimuli important for learning but that this activation rapidly habituates. However, with drugs of abuse this habituation does not occur (Di Chiara 1999). Clearly, the amygdala and specifically the basolateral amygdala has a critical role in memory consolidation and particularly memory involving emotional arousal (Cahill and McGaugh 1998; Cahill et al. 1995; McGaugh 2000). From the present perspective, memory of previous drug experiences and the associations formed by drugs being paired with previously neutral stimuli clearly have a role in unbalancing a reward system already under a heavy allostatic state. How the motivational impact of drug "memories" and drug conditioned reinforcers change with subjects under different levels of allostasis in the reward system, and how specific these drug-related memories are compared to generic emotional memories remains to be determined.

\section{SUMMARY AND CONCLUSIONS}

To summarize, the present perspective is that drug addiction represents an allostatic state in the brain reward system reflected in new reward set points, not only by dysregulation of reward circuits per se but also by the activation and recruitment of brain and hormonal stress responses. Allostasis is defined here as the process of achieving stability through change, and allostatic state is defined as a state of chronic deviation of the regulatory system from its normal operating (homeostatic) level. Allostasis from the drug addiction perspective is the process of maintaining apparent reward function stability by recruitment of changes in reward and stress system neurocircuitry. The allostatic state is a chronic deviation of reward thresholds. The hypothesis generated here is that counteradaptive processes such as opponent-processes, that are part of a normal homeostatic limitation of reward function, fail to return within the homeostatic range. Such dysregulations grow with repeated drug intake producing an allostatic state that drives further drug intake, and ultimately compulsive drug intake, and in turn exaggerates the allostatic state.

Dysregulation of reward neurotransmission is hypothesized to involve compromised function in the dopamine and opioid peptide systems at the molecular and cellular levels in specific components of the extended amygdala and constitutes part of the allostatic state of the brain reward system. Recruitment of brain and hormonal stress systems is hypothesized to involve both HPA axis and brain stress neurotransmission, notably CRF, NPY and norepinephrine systems, and also contributes to the allostatic state of the brain reward system. The manifestation of this allostatic state as compulsive drug-taking may be expressed through the neural circuits of the cortico-striatal-thalamic loops. The hypothesis is that these are the same circuits that are activated by other psychopathology involving repetitive compulsive behavior. The challenges for future research lie in understanding the vulnerability to addiction in all these neural circuits at all stages of the addiction cycle that contribute to such an allostatic-like pathology.

\section{ACKNOWLEDGMENTS}

This is publication number 13306-NP from The Scripps Research Institute. GFK was supported by National Institutes of Health grants AA06420 and AA08459 from the National Institute on Alcohol Abuse and Alcoholism, DA04043 and DA04398 from the National Institute on Drug Abuse, and DK26741 from the National Institute of Diabetes and Digestive and Kidney Diseases. MLM was supported by Institut National de la Sante et de la Recherche Medicale, Universite de Bordeaux II, and Institut Universitaire de France. The authors would like to thank Drs. Barbara Mason, Bernard Carroll, Floyd Bloom, Markus Heilig, and Ms. Carrie Armel for their extremely helpful comments on the manuscript. The authors also would like to thank Mike Arends, Pat Brennan, and Isabelle Batby for their valuable assistance with manuscript preparation, and Janet Hightower for her tremendous help with the production of the illustrations.

\section{REFERENCES}

Abercrombie ED, Keller RW Jr, Zigmond MJ (1988): Characterization of hippocampal norepinephrine release as measured by microdialysis perfusion: Pharmacological and behavioral studies. Neuroscience 27:897-904

Adinoff B, Martin PR, Bone GH, Eckardt MJ, Roehrich L, George DT, Moss HB, Eskay R, Linnoila M, Gold PW (1990): Hypothalamic-pituitary-adrenal axis functioning and cerebrospinal fluid corticotropin releasing hormone and corticotropin levels in alcoholics after recent and long-term abstinence. Arch Gen Psychiatry 47:325-330

Ahima RS, Garcia MM, Harlan RE (1992): Glucocorticoid regulation of preproenkephalin gene expression in the rat forebrain. Mol Brain Res 16:119-127

Ahmed SH, Koob GF (1997): Cocaine- but not food-seeking behavior is reinstated by stress after extinction. Psychopharmacology 132:289-295

Ahmed SH, Koob GF (1998): Transition from moderate to excessive drug intake: Change in hedonic set point. Science 282:298-300

Ahmed SH, Koob GF (1999): Long-lasting increase in the set point for cocaine self-administration after escalation in rats. Psychopharmacology 146:303-312 
Ahmed SH, Walker JR, Koob GF (2000): Persistent increase in the motivation to take heroin in rats with a history of drug escalation. Neuropsychopharmacology 22:413-421

Albeck DS, Hastings NB, McEwen BS (1994): Effects of adrenalectomy and type I or type II glucocorticoid receptor activation on AVP and CRH mRNA in the rat hypothalamus. Mol Brain Res 26:129-134

Alheid GF, Heimer L (1988): New perspectives in basal forebrain organization of special relevance for neuropsychiatric disorders: The striatopallidal, amygdaloid, and corticopetal components of substantia innominata. Neuroscience 27:1-39

American Psychiatric Association (1994): Diagnostic and Statistical Manual of Mental Disorders, 4th ed. Washington DC, American Psychiatric Press

Angulo JA, McEwen BS (1994): Molecular aspects of neuropeptide regulation and function in the corpus striatum and nucleus accumbens. Brain Res Rev 19:1-18

Anthony JC, Warner LA, Kessler RC (1994): Comparative epidemiology of dependence on tobacco, alcohol, controlled substances, and inhalants: Basic findings from the National Comorbidity Survey. Exp Clin Psychopharmacol 2:244-268

Aston-Jones G, Druhan J (1999): Breaking the chain of addiction. Nature 400:317-319

Barrot M, Marinelli M, Abrous DN, Rouge-Pont F, Le Moal M, Piazza PV (2000): The dopaminergic hyper-responsiveness of the shell of the nucleus accumbens is hormone-dependent. Eur J Neurosci 12:973-979

Baumeister RF, Heatherton TF, Tice DM (1994): Losing Control: How and Why People Fail at Self-Regulation. San Diego, Academic Press

Baxter LR Jr, Sanjaya S, Brody AL, Ackermann RF, Colgan M, Schwartz JM, Allen-Martinez Z, Fuster JM, Phelps ME (1996): Brain mediation of obsessive-compulsive disorder symptoms: Evidence from functional brain imaging studies in the human and nonhuman primate. Seminars Clin Neuropsychiatry 1:32-47

Baxter LR Jr, Schwartz JM, Bergman KS, Szuba MP, Guze BH, Mazziotta JC, Alazraki A, Selin CE, Ferng HK, Munford P, Phelps ME (1992): Caudate glucose metabolic rate changes with both drug and behavior therapy for obsessive-compulsive disorder. Arch Gen Psychiatry 49:681-689

Beninger RJ, Hahn BL (1983): Pimozide blocks establishment but not expression of amphetamine-produced environment-specific conditioning. Science 220:1304-1306

Beninger RJ, Herz RS (1986): Pimozide blocks establishment but not expression of cocaine-produced environmentspecific conditioning. Life Sci 38:1425-1431

Beninger RJ, Hoffman DC, Mazurski EJ (1989): Receptor subtype-specific dopaminergic agents and conditioned behavior. Neurosci Biobehav Rev 13:113-122

Bergman J, Kamien JB, Spealman RD (1990): Antagonism of cocaine self-administration by selective dopamine D1 and D2 antagonists. Behav Pharmacol 1:355-363

Berke JD, Hyman SE (2000): Addiction, dopamine, and the molecular mechanisms of memory. Neuron 25:515-532

Bernard C (1865): Introduction a l'Etude de la Medecine Experimentale [Introduction to the Study of Experimental Medicine]. New York, J.B. Ballierre
Bierut LJ, Dinwiddie SH, Begleiter H, Crowe RR, Hesselbrock V, Nurnberger JI Jr, Porjesz B, Schuckit MA, Reich $\mathrm{T}$ (1998): Familial transmission of substance dependence: Alcohol, marijuana, cocaine, and habitual smoking - a report from the Collaborative Study on the Genetics of Alcoholism. Arch Gen Psychiatry 55:982-988

Burchfield S (1979): The stress responses: A new perspective. Psychosom Med 41:661-672

Burns LH, Robbins TW, Everitt BJ (1993): Differential effects of excitotoxic lesions of the basolateral amygdala, ventral subiculum and medial prefrontal cortex on responding with conditioned reinforcement and locomotor activity potentiated by intra-accumbens infusions of D-amphetamine. Behav Brain Res 55:167-183

Cador M, Ahmed SH, Koob GF, Le Moal M, Stinus L (1992): Corticotropin-releasing factor induces a place aversion independent of its neuroendocrine role. Brain Res 597:304-309

Cador M, Robbins TW, Everitt BJ (1989): Involvement of the amygdala in stimulus-reward associations: interaction with the ventral striatum. Neuroscience 30:77-86

Cadoret R, Troughton E, Woodworth G (1994): Evidence of heterogeneity of genetic effect in Iowa adoption studies. Ann NY Acad Sci 708:59-71

Cadoret RJ, Troughton E, O'Gorman TW, Heywood E (1986): An adoption study of genetic and environmental factors in drug abuse. Arch Gen Psychiatry 43:1131-1136

Cahill L, Babinsky R, Markowitsch HJ, McGaugh JL (1995): The amygdala and emotional memory. Nature 377:295-296

Cahill L, McGaugh JL (1998): Mechanisms of emotional arousal and lasting declarative memory. Trends Neurosci 21:294-299

Caine SB, Heinrichs SC, Coffin VL, Koob GF (1995): Effects of the dopamine D1 antagonist SCH 23390 microinjected into the accumbens, amygdala or striatum on cocaine self-administration in the rat. Brain Res 692:47-56

Caine SB, Koob GF (1993): Modulation of cocaine selfadministration in the rat through D-3 dopamine receptors. Science 260:1814-1816

Caldji C, Tannenbaum B, Sharma S, Francis D, Plotsky PM, Meaney MJ (1998): Maternal care during infancy regulates the development of neural systems mediating the expression of fearfulness in the rat. Proc Natl Acad Sci U S A 95:5335-5340

Cannon WB, Rosenblueth A (1933): Studies on conditions of activity in endocrine organs. XXIX. Sympathin E and sympathin I. Am J Physiol 104:557-574

Carr LG, Foroud T, Bice P, Gobbett T, Ivashina J, Edenberg H, Lumeng L, Li TK (1998): A quantitative trait locus for alcohol consumption in selectively bred rat lines. Alcohol Clin Exp Res 22:884-887

Carroll ME (1985): The role of food deprivation in the maintenance and reinstatement of cocaine-seeking behavior in rats. Drug Alcohol Depend 16:95-109

Carroll ME, France CP, Meisch RA (1979): Food deprivation increases oral and intravenous drug intake in rats. Science 205:319-321

Carroll ME, Lac ST (1993): Autoshaping i.v. cocaine selfadministration in rats: Effects of nondrug alternative reinforcers on acquisition. Psychopharmacology 110:5-12 
Carroll ME, Lac ST, Nygaard SL (1989): A concurrently available nondrug reinforcer prevents the acquisition or decreases the maintenance of cocaine-reinforced behavior. Psychopharmacology 97:23-29

Carroll ME, Rodefer JS (1993): Income alters choice between drug and an alternative nondrug reinforcer in monkeys. Exp Clin Psychopharmacol 1:110-120

Celerier E, Laulin J-P, Larcher A, Le Moal M, Simonnet G (1999): Evidence for opiate-activated NMDA processes masking opiate analgesia in rats. Brain Res 847:18-25

Chao HM, McEwen BS (1990): Glucocorticoid regulation of preproenkephalin messenger ribonucleic acid in the rat striatum. Endocrinology 126:3124-3130

Chen JP, Paredes W, Lowinson JH, Gardner EL (1991): Strainspecific facilitation of dopamine efflux by delta 9-tetrahydrocannabinol in the nucleus accumbens of rat: An in vivo microdialysis study. Neurosci Lett 129:136-180

Childress AR, Mozley PD, McElgin W, Fitzgerald J, Reivich M, O'Brien CP (1999): Limbic activation during cueinduced cocaine craving. Am J Psychiatry 156:11-18

Chrousos GP, Gold PW (1992): The concepts of stress and stress system disorders. Overview of physical and behavioral homeostasis. J Am Med Assoc 267:1244-1252

Collins AC, Bhat RV, Pauly JR, Marks MJ (1990): Modulation of nicotine receptors by chronic exposure to nicotinic agonists and antagonists. In Bock G, Marsh J (eds), The Biology of Nicotine Dependence (Series title: Ciba Foundation Symposium, Vol 152). New York, John Wiley, pp 87-105

Colpaert FC (1996): System theory of pain and of opiate analgesia: No tolerance to opiates. Pharmacol Rev 48:355-402

Corrigall WA, Coen KM, Adamson KL (1994): Self-administered nicotine activates the mesolimbic dopamine system through the ventral tegmental area. Brain Res 653:278-284

Corrigall WA, Franklin KBJ, Coen KM, Clarke PBS (1992): The mesolimbic dopaminergic system is implicated in the reinforcing effects of nicotine. Psychopharmacology 107:285-289

Crabbe JC (1989): Genetic animal models in the study of alcoholism. Alcohol Clin Exp Res 13:120-127

Crabbe JC, Phillips TJ, Buck KJ, Cunningham CL, Belknap JK (1999): Identifying genes for alcohol and drug sensitivity: Recent progress and future directions. Trends Neurosci 22:173-179

Crews FT (1999): Alcohol and neurodegeneration. CNS Drug Rev 5:379-394

Cummings S, Elde R, Ells J, Lindall A (1983): Corticotropinreleasing factor immunoreactivity is widely distributed within the central nervous system of the rat: An immunohistochemical study. J Neurosci 3:1355-1368

Dani JA, Heinemann S (1996): Molecular and cellular aspects of nicotine abuse. Neuron 16:905-908

David V, Gold LH, Koob GF, Cazala P (2000): Anxiogeniclike effects limit rewarding effects of cocaine in BALB/ cByJ mice. Neuropsychopharmacology, In Press

Davis M (1997): Neurobiology of fear responses: The role of the amygdala. J Neuropsychiatry Clin Neurosci 9:382-402
De Kloet ER (1991): Brain corticosteroid receptor balance and homeostatic control. Frontiers Neuroendocrinol 12:95-164

De la Garza R, Johanson CE (1987): The effects of food deprivation on the self-administration of psychoactive drugs. Drug Alcohol Depend 19:17-27

de Quidt ME, Emson PC (1986): Distribution of neuropeptide Y-like immunoreactivity in the rat central nervous system. II. Immunohistochemical analysis. Neuroscience 18:545-618

Deminiere JM, Piazza PV, Guegan G, Abrous N, Maccari S, Le Moal M, Simon H (1992): Increased locomotor response to novelty and propensity to intravenous amphetamine self-administration in adult offspring of stressed mothers. Brain Res 586:135-139

Deminiere JM, Piazza PV, Le Moal M, Simon H (1989): Experimental approach to individual vulnerability to psychostimulant addiction. Neurosci Biobehav Rev 13:141-147

Deroche V, Marinelli M, Le Moal M, Piazza PV (1997): Glucocorticoids and behavioral effects of psychostimulants: II. Cocaine intravenous self-administration and reinstatement depend on glucocorticoid levels. J Pharmacol Exp Ther 281:1401-1407

Devor EJ, Cloninger CR (1989): Genetics of alcoholism. Annu Rev Genet 23:19-36

Di Chiara G (1999): Drug addiction as dopamine-dependent associative learning disorder. Eur J Pharmacol 375:13-30

Eckardt MJ, File SE, Gessa GL, Grant KA, Guerri C, Hoffman PL, Kalant H, Koob GF, Li TK, Tabakoff B (1998): Effects of moderate alcohol consumption on the central nervous system. Alcohol Clin Exp Res 22:998-1040

Ehlers CL, Somes C, Lumeng L, Li TK (1999): Electrophysiological response to neuropeptide Y (NPY) in alcoholnaive preferring and non-preferring rats. Pharmacol Biochem Behav 63:291-299

Engel JA, Enerback C, Fahlke C, Hulthe P, Hard E, Johannessen K, Svensson L, Soderpalm B (1992): Serotonergic and dopaminergic involvement in ethanol intake. In Naranjo CA, Sellers EM (eds), Novel Pharmacological Interventions for Alcoholism. New York, Springer, pp 68-82

Epping-Jordan MP, Markou A, Koob GF (1998): The dopamine D-1 receptor antagonist SCH 23390 injected into the dorsolateral bed nucleus of the stria terminalis decreased cocaine reinforcement in the rat. Brain Res 784:105-115

Ettenberg A, Pettit HO, Bloom FE, Koob GF (1982): Heroin and cocaine intravenous self-administration in rats: Mediation by separate neural systems. Psychopharmacology 78:204-209

Everitt BJ, Parkinson JA, Olmstead MC, Arroyo M, Robledo P, Robbins TW (1999): Associative processes in addiction and reward: The role of amygdala-ventral striatal subsystems. Ann NY Acad Sci 877:412-438

Exner E, Clark D (1993): Behaviour in the novel environment predicts responsiveness to d-amphetamine in the rat: A multivariate approach. Behav Pharmacol 4:47-56

Fitzgerald LW, Nestler EJ (1995): Molecular and cellular adaptations in signal transduction pathways following ethanol exposure. Clin Neurosci 3:165-173 
Fratta W, Martellotta MC, Cossu G, Fattore L (1997): WIN $55,212-2$ induces intravenous self-administration in drug-naive mice. Society Neurosci Abstr 23:1869

Fride E, Weinstock M (1989): Alterations in behavioral and striatal dopamine asymmetries induced by prenatal stress. Pharmacol Biochem Behav 32:425-430

Frye GD, Breese GR (1982): GABAergic modulation of ethanol-induced motor impairment. J Pharmacol Exp Ther 223:750-756

Gardner EL, Paredes W, Smith D, Donner A, Milling C, Cohen D, Morrison D (1988): Facilitation of brain stimulation reward by delta-9-tetrahydrocannabinol. Psychopharmacology 96:142-144

Gatto GJ, McBride WJ, Murphy JM, Lumeng L, Li TK (1994): Ethanol self-infusion into the ventral tegmental area by alcohol-preferring rats. Alcohol 11:557-564

Gawin FH, Kleber HD (1986): Abstinence symptomatology and psychiatric diagnosis in cocaine abusers: Clinical observations. Arch Gen Psychiatry 43:107-113

George FR, Goldberg SR (1989): Genetic approaches to the analysis of addiction processes. Trends Pharmacol Sci 10:78-83

Goeders NE, Guerin GF (1994): Non-contingent electric footshock facilities the acquisition of intravenous cocaine self-administration in rats. Psychopharmacology 114: 63-70

Goldberg SR, Woods JH, Schuster CR (1971): Nalorphineinduced changes in morphine self-administration in rhesus monkeys. J Pharmacol Exp Ther 176:464-471

Goodwin DW, Schulsinger F, Hermansen L, Guze SB, Winokur G (1973): Alcohol problems in adoptees raised apart from alcoholic biological parents. Arch Gen Psychiatry 28:238-243

Grant S, London ED, Newlin DB, Villemagne VL, Liu X, Contoreggi C, Phillips RL, Kimes AS, Margolin A (1996): Activation of memory circuits during cue-elicited cocaine craving. Proc Natl Acad Sci U S A 93:12040-12045

Gray TS, Bingaman EW (1996): The amygdala: Corticotropin-releasing factor, steroids, and stress. Crit Rev Neurobiol 10:155-168

Graybiel AM, Aosaki T, Flaherty AW, Kimura M (1994): The basal ganglia and adaptive motor control. Science 265:1826-1831

Härfstrand A, Fuxe K, Cintra A, Agnati LF, Zini I, Wikstrom AC, Okret S, Yu ZY, Goldstein M, Steinbusch H, Verhofstad A, Gustafsson J-A (1986): Glucocorticoid receptor immunoreactivity in monoaminergic neurons of rat brain. Proc Natl Acad Sci U S A 83:9779-9783

Heath AC, Bucholz KK, Madden PA, Dinwiddie SH, Slutske WS, Bierut LJ, Statham DJ, Dunne MP, Whitfield JB, Martin NG (1997a): Genetic and environmental contributions to alcohol dependence risk in a national twin sample: Consistency of findings in women and men. Psychol Med 27:1381-1396

Heath AC, Madden PAF (1998): Statistical methods in genetic research on smoking. Stat Methods Med Res 7:165-186

Heath AC, Slutske WS, Madden PAF (1997b): Gender differences in the genetic contribution to alcoholism risk and to alcohol consumption patterns. In Wilsnack RW, Wil- snack SC (eds), Gender and Alcohol (Series title: Alcohol, Culture, and Social Control Monograph Series, Vol 3). New Brunswick NJ, Rutgers University Press, pp 114-149

Heilig M, Koob GF, Ekman R, Britton KT (1994): Corticotropin-releasing factor and neuropeptide $\mathrm{Y}$ : Role in emotional integration. Trends Neurosci 17:80-85

Heimer L, Alheid G (1991): Piercing together the puzzle of basal forebrain anatomy. In Napier TC, Kalivas PW, Hanin I (eds), The Basal Forebrain: Anatomy to Function. New York, Plenum Press, pp 1-42

Heimer L, Zahm DS, Churchill L, Kalivas PW, Wohltmann C (1991): Specificity in the projection patterns of accumbal core and shell in the rat. Neuroscience 41:89-125

Heinrichs SC, Britton KT, Koob GF (1991): Both conditioned taste preference and aversion induced by corticotropinreleasing factor. Pharmacol Biochem Behav 40:717-721

Heinrichs SC, Menzaghi F, Schulteis G, Koob GF, Stinus L (1995): Suppression of corticotropin-releasing factor in the amygdala attenuates aversive consequences of morphine withdrawal. Behav Pharmacol 6:74-80

Hennessy JW, Levine S (1979): Stress, arousal, and the pituitary-adrenal system: A psychoendocrine hypothesis. In Sprague JM, Epstein AN (eds), Progress in Psychobiology and Physiological Psychology, 8th ed. New York, Academic Press, pp 133-178

Henry C, Kabbaj M, Simon H, Le Moal M, Maccari S (1994): Prenatal stress increases the hypothalamo-pituitaryadrenal axis response in young and adult rats. J Neuroendocrinol 6:341-345

Henry DJ, White FJ (1991): Repeated cocaine administration causes persistent enhancement of D1 dopamine receptor sensitivity within the rat nucleus accumbens. J Pharmacol Exp Ther 258:882-890

Herkenham M, Lynn AB, Little MD, Johnson MR, Melvin LS, de Costa BR, Rice KC (1990): Cannabinoid receptor localization in brain. Proc Natl Acad Sci U S A 87:19321936

Heyser CJ, Roberts AJ, Schulteis G, Koob GF (1999): Central administration of an opiate antagonist decreases oral ethanol self-administration in rats. Alcohol Clin Exp Res 23:1468-1476

Higgins ST, Bickel WK, Hughes JR (1994): Influence of an alternative reinforcer on human cocaine self-administration. Life Sci 55:179-187

Hiroi N, White NM (1991): The lateral nucleus of the amygdala mediates expression of the amphetamineproduced conditioned place preference. J Neurosci 11:2107-2116

Hoffman PL, Rabe CS, Moses F, Tabakoff B (1989): $\mathrm{N}$-methyl-D-aspartate receptors and ethanol: Inhibition of calcium flux and cyclic GMP production. J Neurochem 52:1937-1940

Hooks MS, Colvin AC, Juncos JL, Justice JB Jr (1992a): Individual differences in basal and cocaine-stimulated extracellular dopamine in the nucleus accumbens using quantitative microdialysis. Brain Res 587:306-312

Hooks MS, Jones GH, Juncos JL, Neill DB, Justice JB (1994a): Individual differences in schedule-induced and conditioned behaviors. Behav Brain Res 60:199-209 
Hooks MS, Jones GH, Liem BJ, Justice JB Jr (1992b): Sensitization and individual differences to IP amphetamine, cocaine, or caffeine following repeated intracranial amphetamine infusions. Pharmacol Biochem Behav 43:815-823

Hooks MS, Jones GH, Neill DB, Justice JB Jr (1992c): Individual differences in amphetamine sensitization: Dosedependent effects. Pharmacol Biochem Behav 41:203-210

Hooks MS, Jones GH, Smith AD, Neill DB, Justice JB Jr (1991): Response to novelty predicts the locomotor and nucleus accumbens dopamine response to cocaine. Synapse 9:121-128

Hooks MS, Juncos JL, Justice JB Jr, Meiergerd SM, Povlock SL, Schenk JO, Kalivas PW (1994b): Individual locomotor response to novelty predicts selective alterations in D1 and D2 receptors and mRNAs. J Neurosci 14:6144-6152

Hrubec Z, Omenn GS (1981): Evidence of genetic predisposition to alcoholic cirrhosis and psychosis: Twin concordances for alcoholism and its biological end points by zygosity among male veterans. Alcohol Clin Exp Res 5:207-215

Hwang BH, Zhang JK, Ehlers CL, Lumeng L, Li TK (1999): Innate differences of neuropeptide Y (NPY) in hypothalamic nuclei and central nucleus of the amygdala between selectively bred rats with high and low alcohol preference. Alcohol Clin Exp Res 23:1023-1030

Hyman SE (1996): Addiction to cocaine and amphetamine. Neuron 16:901-904

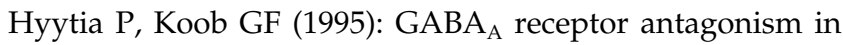
the extended amygdala decreases ethanol self-administration in rats. Eur J Pharmacol 283:151-159

Jenck F, Moreau JL, Martin JR, Kilpatrick GJ, Reinscheid RK, Monsma FJ Jr, Nothacker HP, Civelli O (1997): Orphanin FQ acts as an anxiolytic to attenuate behavioral responses to stress. Proc Natl Acad Sci USA 94:14854-14858

Jentsch JD, Taylor JR (1999): Impulsivity resulting from frontostriatal dysfunction in drug abuse: Implications for the control of behavior by reward-related stimuli. Psychopharmacology 146:373-390

Joels M, de Kloet ER (1992): Control of neuronal excitability by corticosteroid hormones. Trends Neurosci 15:25-30

Joels M, de Kloet ER (1994): Mineralocorticoid and glucocorticoid receptors in the brain. Implications for ion permeability and transmitter systems. Prog Neurobiol 43:1-36

Johnson EO, Kamilaris TC, Chrousos GP, Gold PW (1992): Mechanisms of stress: A dynamic overview of hormonal and behavioral homeostasis. Neurosci Biobehav Rev 16:115-130

Johnston JB (1923): Further contributions to the study of the evolution of the forebrain. J Comp Neurol 35:337-481

June HL, Colker RE, Domangue KR, Perry LE, Hicks LH, June PL, Lewis MJ (1992): Ethanol self-administration in deprived rats: Effects of Ro15-4513 alone, and in combination with flumazenil (Ro15-1788). Alcohol Clin Exp Res 16:11-16

Kaij L (1960): Alcoholism in Twins: Studies on the Etiology and Sequels of Abuse of Alcohol. Stockholm, Almqvist and Wiksell

Kavaliers M (1990): Inhibitory influences of mammalian FMRFamide (Phe-Met-Arg-Phe-amide)-related peptides on nociception and morphine- and stress-induced analgesia in mice. Neurosci Lett 115:307-312

Kessler RC, McGonagle KA, Zhao S, Nelson CB, Hughes M, Eshleman S, Wittchen HU, Kendler KS (1994): Lifetime and 12-month prevalence of DSM-III-R psychiatric disorders in the United States: Results from the National Comorbidity Survey. Arch Gen Psychiatry 51:8-19

Kissin B, Gross MM (1968): Drug therapy in alcoholism. Am J Psychiatry 125:31-41

Koob GF (1992): Drugs of abuse: Anatomy, pharmacology, and function of reward pathways. Trends Pharmacol Sci 13:177-184

Koob GF (1995): Animal models of drug addiction. In Bloom FE, Kupfer DJ (eds), Psychopharmacology: The Fourth Generation of Progress. New York, Raven Press, pp 759-772

Koob GF (1999a): Corticotropin-releasing factor, norepinephrine and stress. Biol Psychiatry 46:1167-1180

Koob GF (1999b): The role of the striatopallidal and extended amygdala systems in drug addiction. Ann N Y Acad Sci 877:445-460

Koob GF, Bloom FE (1988): Cellular and molecular mechanisms of drug dependence. Science 242:715-723

Koob GF, Carrera R, Gold L, Heyser C, Maldonado-Irizarry C, Markou A, Parsons L, Roberts A, Schulteis G, Stinus L, Walker J, Weissenborn R, Weiss F (1998a): Substance dependence as a compulsive behavior. J Psychopharmacol 12:39-48

Koob GF, Heinrichs SC, Menzaghi F, Pich EM, Britton KT (1994): Corticotropin releasing factor, stress and behavior. Semin Neurosci 6:221-229

Koob GF, Le HT, Creese I (1987): The D-1 dopamine receptor antagonist SCH 23390 increases cocaine self-administration in the rat. Neurosci Lett 79:315-320

Koob GF, Le Moal M (1997): Drug abuse: Hedonic homeostatic dysregulation. Science 278:52-58

Koob GF, Markou A, Weiss F, Schulteis G (1993): Opponent process and drug dependence: Neurobiological mechanisms. Semin Neurosci 5:351-358

Koob GF, Pettit HO, Ettenberg A, Bloom FE (1984): Effects of opiate antagonists and their quaternary derivatives on heroin self-administration in the rat. J Pharmacol Exp Ther 229:481-486

Koob GF, Sanna PP, Bloom FE (1998b): Neuroscience of addiction. Neuron 21:467-476

Korf J, Aghajanian GK, Roth RH (1973): Increased turnover of norepinephrine in the rat cerebral cortex during stress: Role of the locus coeruleus. Neuropharmacology 12:933-938

Kornetsky C, Bain G (1990): Brain-stimulation reward: A model for drug induced euphoria. In Adler MW, Cowan A (eds), Modern Methods in Pharmacology Testing and Evaluation of Drugs of Abuse. New York, Wiley-Liss, pp 211-231

Koskenvuo M, Langinvainio H, Kaprio J, Lonnqvist J, Tienari P (1984): Psychiatric hospitalization in twins. Acta Genet Med Gemellol 33:321-332

Kreek MJ (1987): Multiple drug abuse patterns and medical consequences. In Meltzer HY (ed), Psychopharmacol- 
ogy: The Third Generation of Progress. New York, Raven Press, pp 1597-1604

Kreek MJ (1992): Rationale for maintenance pharmacotherapy of opiate dependence. In O'Brien CP, Jaffe JH (eds), Addictive States. New York, Raven Press, pp 205-230

Kreek MJ, Koob GF (1998): Drug dependence: Stress and dysregulation of brain reward pathways. Drug Alcohol Depend 51:23-47

Kreek MJ, Ragunath J, Plevy S, Hamer D, Schneider B, Hartman N (1984): ACTH, cortisol and beta-endorphin response to metyrapone testing during chronic methadone maintenance treatment in humans. Neuropeptides $5: 277-278$

Ladd CO, Huot RL, Thrivikraman KV, Nemeroff CB, Meaney MJ, Plotsky PM (2000): Long-term behavioral and neuroendocrine adaptations to adverse early experience. Prog Brain Res 122:81-103

Lake JR, Hebert KM, Payza K, Deshotel KD, Hausam DD, Witherspoon WE, Arcangeli KA, Malin DH (1992): Ana$\log$ of neuropeptide FF attenuates morphine tolerance. Neurosci Lett 146:203-206

Larcher A, Laulin JP, Celerier E, Le Moal M, Simonnet G (1998): Acute tolerance associated with a single opiate administration: Involvement of N-methyl-D-aspartatedependent pain facilitatory systems. Neuroscience 84:583-589

Laulin JP, Celerier E, Larcher A, Le Moal M, Simonnet G (1999): Opiate tolerance to daily heroin administration: An apparent phenomenon associated with enhanced pain sensitivity. Neuroscience 89:631-636

Laulin J-P, Larcher A, Celerier E, Le Moal M, Simonnet G (1998): Long-lasting increased pain sensitivity in rat following exposure to heroin for the first time. Eur J Neurosci 10:782-785

Lee Y, Schulkin J, Davis M (1994): Effect of corticosterone on the enhancement of the acoustic startle reflex by corticotropin releasing factor (CRF). Brain Res 666:93-98

Legault M, Wise RA (1994): Effects of withdrawal from nicotine on intracranial self-stimulation. Society Neurosci Abstr 20:1032

Leith NJ, Barrett RJ (1976): Amphetamine and the reward system: Evidence for tolerance and post-drug depression. Psychopharmacologia 46:19-25

Leone P, Di Chiara G (1987): Blockade of $D_{1}$ receptors by SCH 23390 antagonizes morphine- and amphetamineinduced place preference conditioning. Eur J Pharmacol 135:251-254

Le Moal M (1995): Mesocorticolimbic dopaminergic neurons: Functional and regulatory roles. In Bloom FE, Kupfer DJ (eds), Psychopharmacology: The Fourth Generation of Progress. New York, Raven Press, pp 283-294

Le Moal M, Simon H (1991): Mesocorticolimbic dopaminergic network: Functional and regulatory roles. Physiol Rev 71:155-234

Lepore M, Liu X, Savage V, Matalon D, Gardner EL (1996): Genetic differences in delta 9-tetrahydrocannabinolinduced facilitation of brain stimulation reward as measured by a rate-frequency curve-shift electrical brain stimulation paradigm in three different rat strains. Life Sci 58:PL365-PL372
Lepore M, Vorel SR, Lowinson J, Gardner EL (1995): Conditioned place preference induced by delta 9-tetrahydrocannabinol: Comparison with cocaine, morphine, and food reward. Life Sci 56:2073-2080

Le Sage MG, Stafford D, Glowa JR (1999): Preclinical research on cocaine self-administration: Environmental determinants and their interaction with pharmacological treatment. Neurosci Biobehav Rev 23:717-741

Leshner AI (1999): Science is revolutionizing our view of addiction-and what to do about it. Am J Psychiatry 156:1-3

Li TK (2000): Pharmacogenetics of responses to alcohol and genes that influence alcohol drinking. J Stud Alcohol 61:5-12

Liljequist S, Engel J (1982): Effects of GABAergic agonists and antagonists on various ethanol-induced behavioral changes. Psychopharmacology 78:71-75

Lovinger DM, White G, Weight FF (1989): Ethanol inhibits NMDA-activated ion current in hippocampal neurons. Science 243:1721-1724

Maas LC, Lukas SE, Kaufman MJ, Weiss RD, Daniels SL, Rogers VW, Kukes TJ, Renshaw PF (1998): Functional magnetic resonance imaging of human brain activation during cue-induced cocaine craving. Am J Psychiatry 155:124-126

Maccari S, Piazza PV, Deminiere JM, Lemaire V, Mormede P, Simon H, Angelucci L, Le Moal M (1991): Life eventsinduced decrease of corticosteroid type I receptors is associated with reduced corticosterone feedback and enhanced vulnerability to amphetamine self-administration. Brain Res 547:7-12

Macey DJ, Koob GF, Markou A (2000): CRF and urocortin decreased brain stimulation reward in the rat: Reversal by a CRF receptor antagonist. Brain Res 866:82-91

Maldonado R, Robledo P, Chover AJ, Caine SB, Koob GF (1993): D1 dopamine receptors in the nucleus accumbens modulate cocaine self-administration in the rat. Brain Res 622:105-112

Malin DH, Lake JR, Carter VA, Cunningham JS, Hebert KM, Conrad DL, Wilson OB (1994): The nicotine antagonist mecamylamine precipitates nicotine abstinence syndrome in the rat. Psychopharmacology 115:180-184

Malin DH, Lake JR, Carter VA, Cunningham JS, Wilson OB (1993): Naloxone precipitates nicotine abstinence syndrome in the rat. Psychopharmacology 112:339-342

Malin DH, Lake JR, Hammond MV, Fowler DE, Rogillio RB, Brown SL, Sims JL, Leecraft BM, Yang HYT (1990): FMRFNH2-like mammalian octapeptide: Possible role in opiate dependence and abstinence. Peptides 11:969-972

Malin DH, Lake JR, Short PE, Blossman JB, Lawless BA, Schopen CK, Sailer EE, Burgess K, Wilson OB (1996): Nicotine abstinence syndrome precipitated by an ana$\log$ of neuropeptide FF. Pharmacol Biochem Behav 54:581-585

Markou A, Koob GF (1991): Postcocaine anhedonia: An animal model of cocaine withdrawal. Neuropsychopharmacology 4:17-26

Markou A, Koob GF (1992): Construct validity of a self-stimulation threshold paradigm: Effects of reward and performance manipulations. Physiol Behav 51:111-119 
Markou A, Weiss F, Gold LH, Caine SB, Schulteis G, Koob GF (1993): Animal models of drug craving. Psychopharmacology 112:163-182

Marlatt GA, Gordon JR (1985): Relapse Prevention. New York, Guilford

Mason BJ, Ownby RL (2000): Acamprosate for the treatment of alcohol dependence: A review of double-blind, placebo-controlled trials. CNS Spectrums 5:58-69

Mason BJ, Salvato FR, Williams LD, Ritvo EC, Cutler RB (1999): A double-blind, placebo-controlled study of oral nalmefene for alcohol dependence. Arch Gen Psychiatry 56:719-724

Matthes HW, Maldonado R, Simonin F, Valverde O, Slowe S, Kitchen I, Befort K, Dierich A, Le Meur M, Dolle P, Tzavara E, Hanoune J, Roques B, Kieffer BL (1996): Loss of morphine-induced analgesia, reward effect and withdrawal symptoms in mice lacking the mu-opioid-receptor gene. Nature 383:819-823

McBride WJ, Li TK (1998): Animal models of alcoholism: Neurobiology of high alcohol-drinking behavior in rodents. Crit Rev Neurobiol 12:339-369

McEwen BS (1995): Adrenal steroid actions on brain: Dissecting the fine line between protection and damage. In Friedman MJ, Charney DS, Deutch AY (eds), Neurobiological and Clinical Consequences of Stress: From Normal Adaptation to PTSD. Philadelphia, Lippincott-Raven, pp 135-147

McEwen BS (1998a): Stress, adaptation, and disease: Allostasis and allostatic load. Ann N Y Acad Sci 840:33-44

McEwen BS (1998b): Protective and damaging effects of stress mediators. Seminars Med Beth Israel Deaconess Med Ctr 338:171-179

McEwen BS (2000): Homeostasis. In Fink G (ed), Encyclopedia of Stress, Vol 2, E-M. San Diego, Academic Press, pp 399-400

McEwen BS, Stellar E (1993): Stress and the individual: Mechanisms leading to disease. Arch Intern Med 153:2093-2101

McGaugh JL (2000): Memory: A century of consolidation. Science 287:248-251

McLellan AT, Arndt IO, Metzger DS, Woody GE, O’Brien CP (1993): The effects of psychosocial services in substance abuse treatment. J Am Med Assoc 269:1953-1959

Merikangas KR, Stolar M, Stevens DE, Goulet J, Preisig MA, Fenton B, Zhang H, O'Malley SS, Rounsaville BJ (1998): Familial transmission of substance use disorders. Arch Gen Psychiatry 55:973-979

Merlo-Pich E, Lorang M, Yeganeh M, Rodriguez de Fonseca F, Raber J, Koob GF, Weiss F (1995): Increase of extracellular corticotropin-releasing factor-like immunoreactivity levels in the amygdala of awake rats during restraint stress and ethanol withdrawal as measured by microdialysis. J Neurosci 15:5439-5447

Modell JG, Mountz JM, Curtis GC, Greden JF (1989): Neurophysiologic dysfunction in basal ganglia/limbic striatal and thalamocortical circuits as a pathogenetic mechanism of obsessive-compulsive disorder. J Neuropsychiatry Clin Neurosci 1:27-36

Mogil JS, Grisel JE, Zhangs G, Belknap JK, Grandy DK (1996): Functional antagonism of mu-, delta- and kappa-opioid antinociception by orphanin FQ. Neurosci Lett 214:131-134
Moller C, Wiklund L, Sommer W, Thorsell A, Heilig M (1997): Decreased experimental anxiety and voluntary ethanol consumption in rats following central but not basolateral amygdala lesions. Brain Research 760:94-101

Morency MA, Beninger RJ (1986): Dopaminergic substrates of cocaine-induced place conditioning. Brain Res 399: $33-41$

Moyer JA, Herrenkohl LR, Jacobowitz DM (1978): Stress during pregnancy: Effect on catecholamines in discrete brain regions of offspring as adults. Brain Res 144:173-178

Negus SS, Henriksen SJ, Mattox A, Pasternak GW, Portoghese PS, Takemori AE, Weinger MB, Koob GF (1993): Effect of antagonists selective for $\mathrm{mu}$, delta and kappa opioid receptors on the reinforcing effects of heroin in rats. J Pharmacol Exp Ther 265:1245-1252

Nesse RM, Berridge KC (1997): Psychoactive drug use in evolutionary perspective. Science 278:63-66

Nestler EJ (1996): Under siege: The brain on opiates. Neuron 16:897-900

Nestler EJ, Aghajanian GK (1997): Molecular and cellular basis of addiction. Science 278:58-63

Nestler EJ, Kelz MB, Chen J (1999): FosB: A molecular mediator of long-term neural and behavioral plasticity. Brain Res 835:10-17

O'Brien CP (1997): A range of research-based pharmacotherapies for addiction. Science 278:66-70

Orford J (1985): A Psychological View of Addiction. Chichester, John Wiley

Palmiter RD, Erickson JC, Hollopeter G, Baraban SC, Schwartz MW (1998): Life without neuropeptide Y. Recent Prog Horm Res 53:163-199

Panksepp J (1998): Affective Neuroscience: The Foundations of Human and Animal Emotions. New York, Oxford University Press

Parkinson JA, Olmstead MC, Burns LH, Robbins TW, Everitt BJ (1999): Dissociation in effects of lesions of the nucleus accumbens core and shell on appetitive pavlovian approach behavior and the potentiation of conditioned reinforcement and locomotor activity by D-amphetamine. J Neurosci 19:2401-2411

Parsons LH, Koob, GF, Weiss F (1995): Serotonin dysfunction in the nucleus accumbens of rats during withdrawal after unlimited access to intravenous cocaine. J Pharmacol Exp Ther 274:1182-1191

Pettit HO, Ettenberg A, Bloom FE, Koob GF (1984): Destruction of dopamine in the nucleus accumbens selectively attenuates cocaine but not heroin self-administration in rats. Psychopharmacology 84:167-173

Pfeffer AO, Samson HH (1988): Haloperidol and apomorphine effects on ethanol reinforcement in free-feeding rats. Pharmacol Biochem Behav 29:343-350

Phillips AG, Fibiger HC (1987): Anatomical and neurochemical substrates of drug reward determined by the conditioned place preference technique. In Bozarth MA (ed), Methods of Assessing the Reinforcing Properties of Abused Drugs. New York, Springer-Verlag, pp 275-290

Phillips TJ, Crabbe JC, Metten P, Belknap JK (1994): Localization of genes affecting alcohol drinking in mice. Alcohol Clin Exp Res 18:931-941 
Piazza PV, Deminiere JM, Le Moal M, Simon H (1989): Factors that predict individual vulnerability to amphetamine self-administration. Science 245:1511-1513

Piazza PV, Deroche V, Deminiere JM, Maccari S, Le Moal M, Simon H (1993): Corticosterone in the range of stressinduced levels possesses reinforcing properties: Implications for sensation-seeking behaviors. Proc Natl Acad Sci U S A 90:11738-11742

Piazza PV, Deroche V, Rouge-Pont F, Le Moal M (1998): Behavioral and biological factors associated with individual vulnerability to psychostimulant abuse. NIDA Res Monogr 169:105-133

Piazza PV, Deroche-Gamonent V, Rouge-Pont F, Le Moal M (2000): Vertical shifts in self-administration doseresponse functions predict a drug-vulnerable phenotype predisposing to addiction. J Neurosci 20:4226-4232

Piazza PV, Le Moal M (1997): Glucocorticoids as a biological substrate of reward: Physiological and pathophysiological implications. Brain Res Rev 25:359-372

Piazza PV, Le Moal ML (1996): Pathophysiological basis of vulnerability to drug abuse: Role of an interaction between stress, glucocorticoids, and dopaminergic neurons. Annu Rev Pharmacol Toxicol 36:359-378

Piazza PV, Maccari S, Deminiere JM, Le Moal M, Mormede P, Simon H (1991a): Corticosterone levels determine individual vulnerability to amphetamine self-administration. Proc Natl Acad Sci U S A 88:2088-2092

Piazza PV, Marinelli M, Rouge-Pont F, Deroche V, Maccari S, Simon H, Le Moal M (1996a): Stress, glucocorticoids, and mesencephalic dopaminergic neurons: A pathophysiological chain determining vulnerability to psychostimulant abuse. Nida Res Monogr 163:277-299

Piazza PV, Rouge-Pont F, Deminiere JM, Kharoubi M, Le Moal M, Simon H (1991b): Dopaminergic activity is reduced in the prefrontal cortex and increased in the nucleus accumbens of rats predisposed to develop amphetamine self-administration. Brain Res 567:169-174

Piazza PV, Rouge-Pont F, Deroche V, Maccari S, Simon H, Le Moal M (1996b): Glucocorticoids have state-dependent stimulant effects on the mesencephalic dopaminergic transmission. Proc Natl Acad Sci U S A 93:8716-8720

Pilla M, Perachon S, Sautel F, Garrido F, Mann A, Wermuth CG, Schwartz JC, Everitt BJ, Sokoloff P (1999): Selective inhibition of cocaine-seeking behaviour by a partial dopamine D3 receptor agonist. Nature 400:371-375

Pontieri FE, Tanda G, Di Chiara G (1995): Intravenous cocaine, morphine, and amphetamine preferentially increase extracellular dopamine in the "shell" as compared with the "core" of the rat nucleus accumbens. Proc Natl Acad Sci U S A 92:12304-12308

Pontieri FE, Tanda G, Orzi F, Di Chiara G (1996): Effects of nicotine on the nucleus accumbens and similarity to those of addictive drugs. Nature 382:255-257

Post RM, Weiss SRB (1995): The neurobiology of treatmentresistant mood disorders. In Bloom FE, Kupfer DJ (eds), Psychopharmacology: The Fourth Generation of Progress. New York, Raven Press, pp 1155-1170

Poulos CX, Cappell H (1991): Homeostatic theory of drug tolerance: A general model of physiological adaptation. Psychol Rev 98:390-408
Project MATCH Research Group (1997): Matching alcoholism treatments to client heterogeneity: Project MATCH posttreatment drinking outcomes. J Stud Alcohol 58:7-29

Rassnick S, D’Amico E, Riley E, Koob GF (1993a): GABA antagonist and benzodiazepine partial inverse agonist reduce motivated responding for ethanol. Alcohol Clin Exp Res 17:124-130

Rassnick S, Heinrichs SC, Britton KT, Koob GF (1993b): Microinjection of a corticotropin-releasing factor antagonist into the central nucleus of the amygdala reverses anxiogenic-like effects of ethanol withdrawal. Brain Res 605:25-32

Rassnick S, Stinus L, Koob GF (1993c): The effects of 6-hydroxydopamine lesions of the nucleus accumbens and the mesolimbic dopamine system on oral selfadministration of ethanol in the rat. Brain Res 623:16-24

Richards G, Schoch P, Haefely W (1991): Benzodiazepine receptors: New vistas. Semin Neurosci 3:191-203

Richter RM, Weiss F (1999): In vivo CRF release in rat amygdala is increased during cocaine withdrawal in self-administering rats. Synapse 32:254-261

Richter RM, Zorrilla EP, Basso AM, Koob GF, Weiss F (2000): Altered amygdalar CRF release and increased anxietylike behavior in Sardinian alcohol preferring rats: A microdialysis and behavioral study. Alcohol Clin Exp Res, in press

Robbins TW, Everitt BJ (1995): Central norepinephrine neurons and behavior. In Bloom FE, Kupfer DJ (eds), Psychopharmacology: The Fourth Generation of Progress. New York, Raven Press, pp 363-372

Roberts AJ, Cole M, Koob GF (1996): Intra-amygdala muscimol decreases operant ethanol self-administration in dependent rats. Alcohol Clin Exp Res 20:1289-1298

Roberts AJ, Heyser CJ, Cole M, Griffin P, Koob GF (2000a): Excessive ethanol drinking following a history of dependence: Animal model of allostasis. Neuropsychopharmacology 22:581-594

Roberts AJ, Heyser CJ, McDonald JS, Kieffer BL, Matthes HWD, Koob GF, Gold LH (2000b): Mu opioid receptor knockout mice do not self-administer alcohol. J Pharmacol Exp Ther 293:1002-1008

Roberts AJ, McArthur RA, Hull EE, Post C, Koob GF (1998): Effects of amperozide, 8-OH-DPAT, and FG 5974 on operant responding for ethanol. Psychopharmacology 137:25-32

Roberts DC, Corcoran ME, Fibiger HC (1977): On the role of ascending catecholaminergic systems in intravenous self-administration of cocaine. Pharmacol Biochem Behav 6:615-620

Roberts DCS, Koob GF, Klonoff P, Fibiger HC (1980): Extinction and recovery of cocaine self-administration following 6-hydroxydopamine lesions of the nucleus accumbens. Pharmacol Biochem Behav12:781-787

Robinson TE, Berridge KC (1993): The neural basis of drug craving: An incentive-sensitization theory of addiction. Brain Res Rev 18:247-291

Rodriguez de Fonseca F, Carrera MRA, Navarro M, Koob GF, Weiss F (1997): Activation of corticotropin-releasing factor in the limbic system during cannabinoid withdrawal. Science 276:2050-2054 
Rouge-Pont F, Marinelli M, Le Moal M, Simon H, Piazza PV (1995): Stress-induced sensitization and glucocorticoids. II. Sensitization of the increase in extracellular dopamine induced by cocaine depends on stress-induced corticosterone secretion. J Neurosci 15:7189-7195

Rouge-Pont F, Piazza PV, Kharouby M, Le Moal M, Simon H (1993): Higher and longer stress-induced increase in dopamine concentrations in the nucleus accumbens of animals predisposed to amphetamine self-administration: A microdialysis study. Brain Res 602:169-174

Rudnick G, Clark J (1993): From synapse to vesicle: The reuptake and storage of biogenic amine neurotransmitters. Biochim Biophys Acta 1144:249-263

Russell MAH (1976): What is dependence? In Edwards G (ed), Drugs and Drug Dependence. Lexington MA, Lexington Books, pp 182-187

Samson HH, Tolliver GA, Pfeffer AO, Sadeghi KG, Mills FG (1987): Oral ethanol reinforcement in the rat: Effect of the partial inverse benzodiazepine agonist RO15-4513. Pharmacol Biochem Behav 27:517-519

Sarnyai Z, Biro E, Gardi J, Vecsernyes M, Julesz J, Telegdy G (1995): Brain corticotropin-releasing factor mediates "anxiety-like" behavior induced by cocaine withdrawal in rats. Brain Res 675:89-97

Schenk S, Partridge B (1997): Sensitization and tolerance in psychostimulant self-administration. Pharmacol Biochem Behav 57:543-550

Schluger J, Bodner G, Gunduz M, Ho A, Kreek MJ (1997): Abnormal metyrapone tests during cocaine abstinence. NIDA Res Monogr 178:105

Schoffelmeer AN, Voorn P, Jonker AJ, Wardeh G, Nestby P, Vanderschuren LJ, De Vries TJ, Mulder AH, Tjon GH (1996): Morphine-induced increase in D-1 receptor regulated signal transduction in rat striatal neurons and its facilitation by glucocorticoid receptor activation: Possible role in behavioral sensitization. Neurochem Res 21:1417-1423

Schuckit MA (1994): Low level of response to alcohol as a predictor of future alcoholism. Am J Psychiatry 151:184-189

Schulkin J, Gold PW, McEwen BS (1998): Induction of corticotropin-releasing hormone gene expression by glucocorticoids: Implication for understanding the states of fear and anxiety and allostatic load. Psychoneuroendocrinology 23:219-243

Schulkin J, McEwen BS, Gold PW (1994): Allostasis, amygdala, and anticipatory angst. Neurosci Biobehav Rev 18:385-396

Schulteis G, Ahmed SH, Morse AC, Koob GF, Everitt BJ (2000): Conditioning and opiate withdrawal: The amygdala links neutral stimuli with the agony of overcoming drug addiction. Nature 405:1013-1014

Schulteis G, Heyser CJ, Koob GF (1997): Opiate withdrawal signs precipitated by naloxone following a single exposure to morphine: Potentiation with a second morphine treatment. Psychopharmacology 129:56-65

Schulteis G, Markou A, Gold LH, Stinus L, Koob GF (1994): Relative sensitivity to naloxone of multiple indices of opiate withdrawal: A quantitative dose-response analysis. J Pharmacol Exp Ther 271:1391-1398
Schwartz JM (1997): Obsessive-compulsive disorder. Sci Med 4:14-23

Schwartz JM (1999): A role for volition and attention in the generation of new brain circuitry: Towards a neurobiology of mental force. J Consciousness Stud 6:115-142

Self DW, Nestler EJ (1995): Molecular mechanisms of drug reinforcement and addiction. Annu Rev Neurosci 18: 463-495

Selye H (1936): A syndrome produced by diverse nocuous agents. Nature 138:32

Selye H (1976): The Stress of Life. New York, McGraw-Hill

Shaham Y, Erb S, Leung S, Buczek Y, Stewart J (1998): CP154,526 , a selective, non-peptide antagonist of the corticotropin-releasing factor1 receptor attenuates stress-induced relapse to drug seeking in cocaine- and heroin-trained rats. Psychopharmacology 137:184-190

Shepard JD, Barron KW, Myers DA (2000): Corticosterone delivery to the amygdala increases corticotropin-releasing factor mRNA in the central amygdaloid nucleus and anxiety-like behavior. Brain Res 861:288-295

Sher KJ (1991): Children of Alcoholics: A Critical Appraisal of Theory and Research. Chicago, University of Chicago Press

Shippenberg TS, Herz A, Spanagel R, Bals-Kubik R, Stein C (1992): Conditioning of opioid reinforcement: Neuroanatomical and neurochemical substrates. Ann N Y Acad Sci 654:347-356

Siegel S (1975): Evidence from rats that morphine tolerance is a learned response. J Comp Physiol Psychol 89:489-506

Slot LA, Colpaert FC (1999): Opiate states of memory: Receptor mechanisms. J Neurosci 19:10520-10529

Solomon RL, Corbit JD (1974): An opponent-process theory of motivation. I. Temporal dynamics of affect. Psychol Rev 81:119-145

Spyraki C, Fibiger HC, Phillips AG (1983): Attenuation of heroin reward in rats by disruption of the mesolimbic dopamine system. Psychopharmacology 79:278-283

Stanford SC, Salmon P (1993): Stress: From Synapse to Syndrome. San Diego, Academic Press

Stellar JR, Stellar E (1985): The Neurobiology of Motivation and Reward. New York, Springer-Verlag

Sterling P, Eyer J (1988): Allostasis: A new paradigm to explain arousal pathology. In Fisher S, Reason J (eds), Handbook of Life Stress, Cognition and Health. Chichester, John Wiley, pp 629-649

Sterling P, Eyer J (1981): Biological basis of stress-related mortality. Social Sci Med Part E: Med Psychol 15:3-42

Stinus L, Le Moal M, Koob GF (1990): Nucleus accumbens and amygdala are possible substrates for the aversive stimulus effects of opiate withdrawal. Neuroscience 37:767-773

Stinus L, Nadaud D, Deminiere JM, Jauregui J, Hand TT, Le Moal M (1989): Chronic flupentixol treatment potentiates the reinforcing properties of systemic heroin administration. Biol Psychiatry 26:363-371

Sutton MA, Karanian DA, Self DW (2000): Factors that determine a propensity for cocaine-seeking behavior during abstinence in rats. Neuropsychopharmacology 22:626-641

Suzdak PD, Glowa JR, Crawley JN, Schwartz RD, Skolnick 
P, Paul SM (1986): A selective imidazobenzodiazepine antagonist of ethanol in the rat. Science 234:1243-1247

Swerdlow NR, Koob GF (1987): Dopamine, schizophrenia, mania, and depression: Toward a unified hypothesis of cortico-striato-pallido-thalamic function. Behav Brain Sci 10:197-245

Tanda G, Munzar P, Goldberg SR (2000): Self-administration behavior is maintained by the psychoactive ingredient of marijuana in squirrel monkeys. Nature Neurosci 3:1073-1074

Tanda G, Pontieri FE, Di Chiara G (1997): Cannabinoid and heroin activation of mesolimbic dopamine transmission by a common mu1 opioid receptor mechanism. Science 276:2048-2050

Thiele TE, Marsh DJ, Ste. Marie L, Bernstein IL, Palmiter RD (1998): Ethanol consumption and resistance are inversely related to neuropeptide $\mathrm{Y}$ levels. Nature 396:366-369

Toates F (1990): Motivational Systems. New York, Cambridge University Press

True WR, Heath AC, Scherrer JF, Waterman B, Goldberg J, Lin N, Eisen SA, Lyons MJ, Tsuang MT (1997): Genetic and environmental contributions to smoking. Addiction 92:1277-1287

Uhl GR, Elmer GI, LaBuda MC, Pickens RW (1995): Genetic influences in drug abuse. In Bloom FE, Kupfer DJ (eds), Psychopharmacology: The Fourth Generation of Progress. New York, Raven Press, pp 1793-1806

Vaccarino FJ, Pettit HO, Bloom FE, Koob GF (1985): Effects of intracerebroventricular administration of methyl naloxonium chloride on heroin self-administration in the rat. Pharmacol Biochem Behav 23:495-498

Valentino RJ, Foote SL, Page ME (1993): The locus coeruleus as a site for integrating corticotropin-releasing factor and noradrenergic mediation of stress responses. Ann N Y Acad Sci 697:173-188

Van Bockstaele EJ, Colago EE, Valentino RJ (1998): Amygdaloid corticotropin-releasing factor targets locus coeruleus dendrites: Substrate for the co-ordination of emotional and cognitive limbs of the stress response. J Neuroendocrinol 10:743-757

Vezzani A, Sperk G, Colmers WF (1999): Neuropeptide Y: Emerging evidence for a functional role in seizure modulation. Trends Neurosci 22:25-30

Volkow ND, Fowler JS (2000): Addiction, a disease of compulsion and drive: Involvement of the orbitofrontal cortex. Cerebral Cortex 10:318-325

Volkow ND, Wang GJ, Fowler JS, Hitzemann R, Angrist B, Gatley SJ, Logan J, Ding YS, Pappas N (1999): Association of methylphenidate-induced craving with changes in right striato-orbitofrontal metabolism in cocaine abusers: Implications in addiction. Am J Psychiatry 156:19-26

Wahlestedt C, Karoum F, Jaskiw G, Wyatt RJ, Larhammar D, Ekman R, Reis DJ (1991): Cocaine-induced reduction of brain neuropeptide $\mathrm{Y}$ synthesis dependent on medial prefrontal cortex. Proc Natl Acad Sci USA 88:2078-2082
Waltman C, McCaul ME, Wand GS (1994): Adrenocorticotropin responses following administration of ethanol and ovine corticotropin-releasing hormone in the sons of alcoholics and control subjects. Alcohol Clin Exp Res 18:826-830

Watkins SS, Stinus L, Koob GF, Markou A (2000): Reward and somatic changes during precipitated nicotine withdrawal in rats: Centrally and peripherally mediated effects. J Pharmacol Exp Ther 292:1053-1064

Weddington WW Jr, Brown BS, Haertzen CA, Hess JM, Mahaffey JR, Kolar AF, Jaffe JH (1991): Comparison of amantadine and desipramine combined with psychotherapy for treatment of cocaine dependence. Am J Drug Alcohol Abuse 17:137-152

Weeks JR, Collins RJ (1976): Changes in morphine selfadministration in rats induced by prostaglandin E1 and naloxone. Prostaglandins 12:11-19

Weiss F, Hurd YL, Ungerstedt U, Markou A, Plotsky PM, Koob GF (1992a): Neurochemical correlates of cocaine and ethanol self-administration. Ann N Y Acad Sci 654:220-241

Weiss F, Markou A, Lorang MT, Koob GF (1992b): Basal extracellular dopamine levels in the nucleus accumbens are decreased during cocaine withdrawal after unlimitedaccess self-administration. Brain Research 593:314-318

Weiss F, Parsons LH, Schulteis G, Hyytia P, Lorang MT, Bloom FE, Koob GF (1996): Ethanol self-administration restores withdrawal-associated deficiencies in accumbal dopamine and 5-hydroxytryptamine release in dependent rats. J Neurosci 16:3474-3485

Weissenborn R, Deroche V, Koob GF, Weiss F (1996): Effects of dopamine agonists and antagonists on cocaineinduced operant responding for a cocaine associated stimulus. Psychopharmacology 126:311-322

White FJ (1996): Synaptic regulation of mesocorticolimbic dopamine neurons. Annu Rev Neurosci 19:405-436

Whitelaw RB, Markou A, Robbins TW, Everitt BJ (1996): Excitotoxic lesions of the basolateral amygdala impair the acquisition of cocaine-seeking behaviour under a second-order schedule of reinforcement. Psychopharmacology 127:213-224

Wikler A (1973): Dynamics of drug dependence: Implications of a conditioning theory for research and treatment. Arch Gen Psychiatry 28:611-616

Woldbye DP, Klemp K, Madsen TM (1998): Neuropeptide Y attenuates naloxone-precipitated morphine withdrawal via Y5-like receptors. J Pharmacol Exp Ther 284:633-636

Woolverton WL, Virus RM (1989): The effects of a D1 and D2 dopamine antagonist on behavior maintained by cocaine or food. Pharmacol Biochem Behav 32:691-697

World Health Organization (1992): International Statistical Classification of Diseases and Related Problems, 10th ed. Geneva, World Health Organization

Yokel RA, Wise RA (1975): Increased lever pressing for amphetamine after pimozide in rats: Implications for a dopamine theory of reward. Science 187:547-549 